\title{
Nuevas perspectivas conceptuales en la afirmación del derecho a la igualdad de las personas con discapacidad mental: una evaluación crítica de la jurisprudencia del Tribunal Constitucional peruano ${ }^{1}$
}

\author{
New conceptual perspectives in the affirmation of the \\ right to equality of persons with mental disabilities: \\ a critical evaluation of the Peruvian Constitutional \\ Court case law
}

\author{
Marco Alonso Rodríguez Gamero ${ }^{2}$ \\ Pontificia Universidad Católica del Perú \\ rodriguez.marco@pucp.pe
}

\footnotetext{
1 La presente investigación ha sido desarrollada en el marco del proyecto "Contribución de la jurisprudencia del Tribunal Constitucional a la afirmación del derecho a la igualdad y no discriminación para grupos en situación de especial vulnerabilidad en el Perú: mujeres y niñas, pueblos indígenas, reclusos, personas con discapacidad mental y población LGBTI (2001-2016), considerando la constante injusticia y marginación social que enfrentan estos grupos vulnerables, y que estas variables se intersectan" (ID 570). Este proyecto del Grupo de Investigación en Derecho Constitucional y Derechos Fundamentales es financiado por el Vicerrectorado de Investigación de la Pontificia Universidad Católica del Perú. Agradezco, además, a Abraham Siles, César Landa, David Lovatón, Elena Alvites y Juan Carlos Díaz por sus valiosos comentarios al artículo.

2 Egresado de la Facultad de Derecho de la Pontificia Universidad Católica del Perú. Miembro del Grupo de Investigación en Derecho Constitucional y Derechos Fundamentales. Código ORCID: 0000-0003-2293-2098.
} 
Resumen: El presente artículo procura realizar un análisis crítico de las sentencias del Tribunal Constitucional peruano sobre el derecho a la igualdad de las personas con discapacidad mental. Para ello, nos apoyaremos en dos discusiones. La primera es sobre el propio concepto de discapacidad mental, discusión que reflejará el entendimiento de la desventaja, pero, a la vez, nos permitirá atender la crítica sobre la esencialización de los atributos en los enfoques basados en grupos sociales. Esto nos llevará a identificar un movimiento social en formación, que es el de neurodiversidad. La segunda discusión que presentaremos es en torno al modelo de igualdad inclusiva tras la Convención sobre los Derechos de las Personas con Discapacidad, de Naciones Unidas, que es una perspectiva multidimensional para reparar la desventaja que experimentan las personas con discapacidad. Analizaremos si este modelo es compatible con el enfoque asimétrico que postula el Tribunal, basado en el concepto de igualdad real de oportunidades. Finalizaremos con una lectura crítica de los desarrollos del Tribunal Constitucional sobre este grupo desaventajado.

Palabras clave: personas con discapacidad mental, igualdad, igualdad real de oportunidades, Tribunal Constitucional, neurodiversidad, igualdad inclusiva.

Abstract: This article aims to realise a critical analysis of the decisions of the Peruvian Constitutional Court on the right to equality of people with mental disabilities. To do this, we will rely on two discussions. The first is about the concept of mental disability itself, a discussion that will reflect the understanding of the disadvantage, but, at the same time, will allow us to address criticism about the essentialization of attributes in social group-based approaches. This will lead us to identify the neurodiversity movement. The second discussion we will present is about the model of inclusive equality after the United Nations Convention on the Rights of Persons with Disabilities, which is a multidimensional perspective to repair the disadvantage experienced by persons with disabilities. We will analyze whether this model is compatible with the asymmetric approach proposed by the peruvian Court, based on the concept of real equality of opportunities. We will conclude with a critical reading of the developments of the Constitutional Court on this disadvantaged group. 
Keywords: Persons with mental disabilities, equality, real equality of opportunities, Constitutional Court, neurodiversity, inclusive equality.

\section{Introducción}

En los dos últimos siglos hemos sido testigos de cómo los sistemas políticos han empezado a reconocer a la persona "en la especificidad de sus diversos status sociales, en relación a distintos criterios de diferenciación" 3 . Las cartas constitucionales han expresado este cambio, pasando de asumir un sujeto nacional ideal ${ }^{4}$ a tratar de manera explícita a ciertos colectivos, en especial a aquellos que comparten una experiencia histórica de exclusión ${ }^{5}$. Estamos, pues, en tiempos donde ha sido desestabilizada la construcción indiferenciada del sujeto político nacional y se demanda, por el contrario, una protección especial hacia aquellos grupos que por mantener características no hegemónicas se han visto en situaciones de marginación estructural. Esto no es otra cosa que afirmar el principio y derecho de igualdad desde el paradigma del Estado constitucional de Derecho.

Como ampliamente ha sido reseñado, las primeras formulaciones constitucionales sobre la igualdad demandaban no diferenciar entre los sujetos ${ }^{6}$, pues hacerlo se asociaba, por ejemplo, con el otorgamiento público de privilegios ${ }^{7}$. Así, la generalidad que caracterizaba a las leyes se imbricaba con el concepto de igualdad, no siendo percibida la necesidad pública de realizar tratos diferenciados hacia aquellos grupos de especial vulnerabilidad $^{8}$. La anterior concepción es lo que tradicionalmente conocemos como igualdad ante la ley, fórmula que es ampliamente recogida por las Constituciones, entre ellas la peruana9

\footnotetext{
3 Bobbio (1991), p. 115; véanse también Alemany (2018), p. 213; Criado (2011), p. 27.

4 Fioravanti (2016), p. 141; Tully (1995), pp. 82-83; Velasco (2004), pp. 199-200.

5 Gargarella (2014), pp. 353-354; SabA (2012), p. 29.

6 Grosman (2008), p. 68; Saba (2012), p. 24; Díaz de Valdés (2015), pp. 169-170.

7 Nogueira (2006), pp. 66-68; ZAgrebelsky (2011), p. 29.

8 Nogueira (2006), p. 67; Díaz de Valdés (2015), p. 171.

9 El inciso 2 del artículo 2 de la Constitución peruana recoge la igualdad ante la ley junto con la prohibición de discriminación: "Toda persona tiene derecho: (...) [a] la igualdad ante la ley. Nadie
} 
En el caso del Perú, al ser esta versión limitada de la igualdad la única fórmula general que es reconocida textualmente en la Constitución ${ }^{10}$, el Tribunal Constitucional tuvo que encargarse de revisar y ampliar esta concepción formal a partir de los propios mandatos sustantivos que emanan de la Carta Fundamental, concebida como un sistema de garantías y valores ${ }^{11}$, en especial de las "exigencias éticas derivadas del principio de dignidad humana"12. Así, nuestro alto Tribunal se encargó de esta ampliación, formulando la igualdad no solo como un derecho, sino también como un principio ${ }^{13}$, además de complementar la clásica dimensión formal de la igualdad con otra más acorde a los postulados materiales de la Constitución.

En un primer momento, el Tribunal reconoció “(...) la insuficiencia de los mandatos prohibitivos de discriminación y la necesidad de equiparar situaciones, per se, desiguales”, es decir, señaló que el Estado debe realizar un "tratamiento diferenciado si es que dos sujetos no se encuentran en una situación igual", en la medida que este sea "razonable y proporcional"14. No obstante, y tal como el propio Tribunal ha declarado con posterioridad $^{15}$, esta primera formulación sustantiva de la igualdad partió de la misma matriz tradicional y simétrica de la dimensión formal de la igualdad, pese a algunos esfuerzos iniciales en dar tratamientos especiales a poblaciones vulnerables ${ }^{16}$. Esta matriz, en suma, soslayaba las

debe ser discriminado por motivo de origen, raza, sexo, idioma, religión, opinión, condición económica o de cualquiera otra índole". Para un análisis sobre los alcances del artículo y la forma de interpretar sus omisiones, véase HUERTA (2005).

10 Una revisión de las críticas hacia la dimensión formal de la igualdad puede revisarse en DíAZ dE VALDÉs (2015), pp. 170-172; Ronconi (2019), p. 107.

11 Fioravanti (2016), p. 128.

12 Sentencia del Tribunal Constitucional $N^{\circ}$ 0033-2010-PI, de 10 de abril de 2012, fundamento jurídico 12.

13 Sentencia del Tribunal Constitucional N 0048-2004-PI, de 1 de abril de 2005, fundamento jurídico 61.

14 Sentencia del Tribunal Constitucional N 0606-2004-AA, de 28 de junio de 2004, fundamento jurídico 11.

15 Sentencia del Tribunal Constitucional N 01272-2017-PA, de 5 de marzo de 2019, fundamentos jurídicos 12-13.

16 Véase, por ejemplo, Sentencia del Tribunal Constitucional $N^{\circ} 0033-2010-P I$, de 10 de abril de 2012, fundamento jurídico 25. 
raíces estructurales y multicausales de la desigualdad ${ }^{17}$.

Es por ello que el Tribunal renovó el contenido de la igualdad constitucional bajo un enfoque estructural, de igualdad como no-sometimiento ${ }^{18}$, y ligado al tratamiento de los grupos desaventajados, más allá de su clásica consideración como categorías prohibidas de discriminación. Según presenta el Tribunal, este nuevo enfoque igualitario aborda el problema de la superación de las desventajas desde una perspectiva cultural (reconocimiento) y socioeconómica (redistribución) ${ }^{19}$. La igualdad material, entonces, debe dimensionarse más allá de las situaciones individuales analizadas y afrontar las causas estructurales que forman las desventajas de estos grupos. En esa línea, el Estado adquiere una serie de obligaciones particulares a favor de estos colectivos en múltiples ámbitos (salud, trabajo, cultura, política, acceso a la justicia, entre otras) ${ }^{20}$, que permitan alcanzar, conforme lo establece nuestro Tribunal, la igualdad real de oportunidades ${ }^{21}$.

Es importante saber, en este contexto, que el enfoque teórico de Nancy Fraser subyace a este nuevo concepto de igualdad que plantea el Tribunal Constitucional peruano. Justamente, al momento de incorporar el

17 Sobre el giro estructural en el análisis del derecho de igualdad, véanse Ronconı (2019), pp. 123-127; Grosman (2008), p. 82; Díaz de ValdÉs (2015), pp. 172-173. Asimismo, en el tercer acápite de este trabajo profundizaremos sobre este asunto.

18 Sobre esta tradición que compite con la de igualdad como no-discriminación, véase GrosmaN (2012).

19 Sentencia del Tribunal Constitucional $N^{\circ}$ 01272-2017-PA, de 5 de marzo de 2019, fundamentos jurídicos 12-13.

20 En otra sentencia, el Tribunal va en el mismo sentido: “(...) al Estado le corresponde remover los obstáculos históricos que han mantenido y mantienen aún en posiciones desventajosas respecto al resto de la sociedad e incluso en situaciones de desigualdad a varios grupos vulnerables". Sentencia del Tribunal Constitucional N 00853-2015-PA, de 14 de marzo de 2017, fundamento jurídico 58 .

21 La inclusión de "real" en esta reciente formulación estructural de la igualdad no es una cuestión meramente accesoria, sino es expresión propia de la tradición de la igualdad como no sometimiento. Véanse RonconI (2019), pp. 127-131; SABA (2012), pp. 13-35. Esta se diferencia de la concepción individualista de la igualdad de oportunidades que previamente había sido trabajada por el Tribunal en la Sentencia del Tribunal Constitucional N 0033-2010-PI, de 10 de abril de 2012, fundamento jurídico 12. Para una mayor profundización de las diferencias de ambos modelos, véase Grosman (2008), pp. 78-85. Respecto a las críticas, entre otras, al enfoque individualista sobre la igualdad de oportunidades, puede revisarse también a DíAZ DE VALDÉs (2015), pp. 176180; FREDMAN (2011), pp. 18-19. 
concepto de igualdad real de oportunidades, el Tribunal hizo referencia a un artículo de esta filósofa estadounidense ${ }^{22}$, como a otro de Laura Clérico y Martín Aldao, autores de Argentina quienes a su vez parten expresamente de las nociones de reconocimiento y redistribución formuladas por Fraser $^{23}$. Y es que esta impronta teórica detrás del concepto de igualdad real de oportunidades es el resultado de los trabajos realizados por la academia argentina ${ }^{24}$, centrales para terminar de comprender el nuevo enfoque igualitario del alto Tribunal peruano.

Así tenemos que para Ronconi, quien sigue también a Fraser ${ }^{25}$, la igualdad real de oportunidades "busca garantizar a todos los individuos el efectivo ejercicio de su plan de vida", para lo cual parte de una "posición intermedia" entre las acciones reparadoras y transformadoras ${ }^{26}$. Esto nos quiere decir que el enfoque de reparación de este modelo estructural de igualdad como no-sometimiento no se limita a lograr "resultados concretos" que permitan "generar las condiciones para garantizar que ciertos grupos alcancen determinados lugares" 27 , sino a ordenar acciones que transformen las estructuras, las "dinámicas sociales" que producen y reproducen la desigualdad ${ }^{28}$ y que "Ilevan a la situación de desventaja al grupo"29.

Ahora bien, esta nueva concepción de la igualdad constitucional que hemos presentado contrasta con aquellas viejas concepciones que asociaban a la pluralidad de grupos en un Estado como un obstáculo al progreso $^{30}$ o la neutralidad del Estado respecto de estas diferencias sociales

22 Sentencia del Tribunal Constitucional Nº1272-2017-PA, de 5 de marzo de 2019, fundamento jurídico 14. El artículo en cuestión era FRASER (1996). Para un mayor análisis, véase el punto 3.2 de este trabajo.

23 Clérico y Aldao (2011).

24 Desde luego, esto es consecuencia de que su Constitución emplee esta fórmula en el numeral 23 de su artículo 75: "Corresponde al Congreso (...) [l]egislar y promover medidas de acción positiva que garanticen la igualdad real de oportunidades y de trato (...)".

25 RonCONI (2019), pp. 128-131.

26 RoNCONI (2019), p. 135.

27 RONCONI (2019), p. 134.

28 Grosman (2008), p. 82.

29 SABA (2012), p. 55.

30 Velasco (2004), pp. 205-206; Tully (1995), pp. 87-91. 
constitucionalmente relevantes ${ }^{31}$. Más aún, pone en primer orden, como objetivo del Estado constitucional de Derecho, la inclusión de la diferencia, lo que supone una especial preocupación por aquellos grupos que, bajo anteriores esquemas, quedaron invisibilizados y marginados del proyecto nacional ${ }^{32}$. Es así que el reto para lograr reparar tales desigualdades estructurales que mantienen esta marginación yace en reconocer las realidades de cada grupo desaventajado, sus diferencias ${ }^{33}$.

Los contornos de las diferencias humanas son múltiples y no se agotan en ámbitos como el género, la edad o el idioma. El caso de las personas con discapacidad mental ${ }^{34}$ representa un reto para la reflexión constitucional, dada la perspectiva unidimensional de racionalidad imbricada en los sistemas políticos ${ }^{35}$, junto a los prejuicios arraigados sobre las características de este grupo social ${ }^{36}$. Todo ello ha llevado por mucho tiempo a considerar que hay razones objetivas que justificaban un trato

31 CRIADo (2011), pp. 19-20.

32 Young (1990), pp. 122-123.

33 Grosman (2008), pp. 28-29.

34 En la parte dogmática del artículo, emplearemos el término de "personas con discapacidad mental" de una manera abierta para incluir también a quienes presentan deficiencias intelectuales. Si bien de manera incipiente se está prefiriendo el término "personas con discapacidad psicosocial", como ocurre en el Decreto Supremo 007-2020-SA, que reglamenta la Ley 30947, Ley de Salud Mental, mantenemos esta elección por el hecho que este término es el que contó con mayor circulación en los pronunciamientos jurisdiccionales. Lo cierto es que en el ordenamiento jurídico peruano no hay una expresión estándar para referirse a este grupo social, tan así que en el artículo 7 de la Constitución peruana se habla de personas incapacitadas a causa de una deficiencia mental y en el artículo 11 de la Ley 26842, Ley General de la Salud, se emplea el término "personas con discapacidad mental". Más allá de lo normativo, debe considerarse que en otras áreas de conocimiento teóricamente se distingue entre discapacidades intelectuales y enfermedades mentales, prefiriéndose emplear al primero. Véase SCHALOCK y LUCKASSON (2013). Por su parte, el término "mental" es objeto también de críticas por su ambigüedad (véanse VARGAS y LóPEZ (2011), pp. 591-592; KAKOULLIS e IKEHARA (2018), p. 56), habiendo sido propuesto adjetivos que incluyan el aspecto cerebral (véase VARGAS (2012), p. 13). Es más, hay críticas hacia la propia expresión "personas con discapacidad", entendida como una fórmula que en estricto no trata a la discapacidad como un producto social. Véanse SHAKESPEARE (2014), p. 19; KaKoullis e IKEHARA (2018), pp. 54-55. Siendo conscientes de estos cuestionamientos, y de la provisionalidad intrínseca de esta mención (véase SHILDRICK (2012), p. 34), emplearemos el término "personas con discapacidad mental" como una categoría operativa que ha permitido canalizar una serie de demandas a favor del reconocimiento de derechos sociales, por lo que la connotación dada aquí no tendrá mayores pretensiones que representar de manera aproximada a este colectivo.

35 Young (2002), p. 9; Rodríguez (2015), pp. 105-107.

36 Arstein-Kerslake (2017), pp. 65-66; Nussbaum (2006), pp. 193-195. 
jurídico diferenciado semejante al que reciben los menores de $\operatorname{edad}^{37}$. No obstante, estos supuestos se han visto doblemente desestabilizados, tanto por la acción de nuevos movimientos sociales como por el establecimiento de un nuevo marco internacional de protección de las personas con discapacidad.

Por un lado, la presencia de formas plurales de entender el fenómeno cognitivo lleva a revisar la base material que subyace al ámbito de protección de las personas con discapacidad mental como grupo desaventajado. Las demandas de reconocimiento de parte del movimiento de neurodiversidad llevan implícito un cuestionamiento al propio concepto de discapacidad mental, al no representar adecuadamente esta etiqueta la realidad de este grupo social que reclama un entorno diseñado no solo para neurotípicos, sino que sea inclusivo de las distintas formas contrahegemónicas de cognición ${ }^{38}$. Por otro lado, a nivel global, desde la entrada en vigor de la Convención sobre los Derechos de las Personas con Discapacidad de Naciones Unidas (CDPD-ONU en adelante) ${ }^{39}$, se ha edificado toda una nueva perspectiva de derechos humanos de la discapacidad mental. Así, la CDPD-ONU y su Protocolo Facultativo han permitido introducir en sede doméstica el modelo multidimensional de igualdad inclusiva de la discapacidad.

Aunque responden a cuestiones distintas, ambos factores que cambian el paradigma tradicional de tratamiento de las personas con discapacidad mental se articulan en la discusión sobre el concepto de igualdad real de oportunidades que introdujo recientemente el Tribunal Constitucional peruano. Así, el primer elemento sobre la neurodiversidad atiende a la crítica reiterada a los enfoques de igualdad basados en categorías de grupo respecto a que esencializan ciertas características, ya que este factor implica revisar la base material del ámbito de protección de las personas

37 Alemany (2018), pp. 202-204.

38 DYCK y RusselL (2020); ORTEGA (2009); LolLINI (2018).

39 La CDPD-ONU entró en vigor el 8 de mayo del 2008, siendo ratificada por el Estado peruano mediante el Decreto Supremo 073-2007-RE. En la actualidad, cuenta con más de 180 Estados parte. Datos obtenidos de: https://treaties.un.org/Pages/ViewDetails.aspx?src=TREATY\&mtdsg_ no=IV-15\&chapter=4\&clang=_en (fecha de acceso: 17 de diciembre del 2019). 
con discapacidad mental, lo que permite, al mismo tiempo, comprender las desventajas que experimenta este grupo ${ }^{40}$. La faz de reconocimiento de la igualdad real de oportunidades demanda, así, una "valorización de las identidades diversas" 41 , lo que supone no dar por sentado y generalizar, desde un análisis constitucional, al grupo humano y su experiencia detrás del concepto de discapacidad mental. El segundo factor relativo al modelo de igualdad inclusiva de la CDPD-ONU nos hace cuestionarnos si el concepto estructural de igualdad, esbozado por el Tribunal bajo la influencia teórica de Fraser, es compatible o puede complementarse con este modelo multidimensional, sobre todo en relación a las desventajas características del grupo de personas con discapacidad mental, que comúnmente han oscilado entre lo individual y lo estructural.

Si ponemos en perspectiva estas disrupciones con los pronunciamientos en materia de igualdad del Tribunal Constitucional peruano sobre la protección de este grupo social heterogéneo, veremos que existen limitaciones en la comprensión de las situaciones estructurales que subyacen a estos casos. Esta situación nos lleva al objetivo de este artículo, que es analizar la evolución jurisprudencial del Tribunal Constitucional a la luz de estos cambios, con el fin de evidenciar sus limitaciones y plantear los retos que debiera asumir si toma en serio el nuevo modelo de igualdad estructural que recientemente adoptó.

Por ello, el enfoque del que parte este trabajo es normativo, en el sentido que trazamos cómo debería cambiar la jurisprudencia constitucional parar ajustarse a estas disrupciones y lograr avanzar en la superación de la desventaja que afecta a las personas con discapacidad mental. Formular este juicio implicó articular dos puntos de vista: uno externo y otro interno. Por un lado, el juicio normativo externo toma como referencia elementos conceptuales propios de la literatura académica sobre discapacidad para evidenciar una serie de desajustes u omisiones en la respuesta jurídica que ha venido brindado el Tribunal Constitucional peruano. A este juicio lo complementamos con uno interno, que parte de

40 Díaz de Valdés (2015), p. 175; Criado (2011), pp. 25-26.

41 RoNCONI (2019), p. 129. 
la CDPD-ONU y su enfoque multidimensional de igualdad. En gran medida, ambos juicios son informados por una literatura distinta a la propia de la dogmática constitucional, pero que aportan, a su vez, una serie de argumentos dirigidos a refinar los presupuestos constitucionales de protección de las personas con discapacidad mental en materia de igualdad.

Considerando lo anterior, este artículo realizará ahora, y en primer lugar, una breve presentación de las aproximaciones clásicas a la discapacidad mental y de las nuevas perspectivas que hay sobre su concepto. Luego, se abordará el nuevo modelo de igualdad que subyace a la CDPD-ONU y la posible articulación que tiene con la propuesta de igualdad real de oportunidades del Tribunal Constitucional peruano. Tratado ambos aspectos, el artículo finalizará con un análisis crítico sobre las sentencias del Tribunal Constitucional en materia de personas con discapacidad mental, que mostrará cómo las concepciones sobre discapacidad implícitas en esta jurisprudencia limitó la reparación de la desventaja de este grupo, así como la necesidad de renovar esta línea jurisprudencial a la luz del enfoque mutidimensional de igualdad de la CDPD-ONU y de experiencias diferenciadas como el de neurodiversidad.

\section{La discapacidad mental como concepto: entre lo individual y lo estructural}

Desde la ratificación por parte del Estado peruano de la CDPD-ONU, los análisis jurídico-constitucionales han encontrado un nuevo marco conceptual para comprender los alcances del principio-derecho de igualdad en las personas con discapacidad mental, no siendo ajeno a este cambio el Tribunal Constitucional peruano ${ }^{42}$. Este marco es el llamado modelo de discapacidad basado en derechos humanos (MDDH en adelante), que se nutre de los fundamentos teóricos del construccionismo social para definir la discapacidad mental ${ }^{43}$.

42 Sentencia del Tribunal Constitucional Nº0194-2014-PHC, de 30 de abril de 2019, fundamentos jurídicos 8-18.

43 Comité sobre los Derechos de las Personas con Discapacidad (2018), p. 3; Arstein-Kerslake (2017), pp. 72-73. 
Si bien la mayor parte de académicos y operadores del Derecho asumen los postulados de este modelo ${ }^{44}$, se han formulado recientemente dos agudas críticas que no pueden ser soslayadas al incidir en la justificación del trato diferenciado que reciben las personas con discapacidad mental ${ }^{45}$, punto de partida para considerarlos como un grupo desaventajado que merece una valorización similar al que reciben, por ejemplo, los pueblos originarios, mujeres, entre otros. Estos cuestionamientos perfilan una serie de atributos al MDDH, que, como sostendremos, pueden ser superados si entendemos que lo normativamente estipulado en la CDPD-ONU es lo suficientemente abierto para evitar su asociación con una formulación extrema del construccionismo social.

Por ello, presentaremos una lectura sintética de las dos formas clásicas de entender la discapacidad mental, la patológica y la construccionista, al permitirnos ilustrar las tensiones entre las visiones individuales y estructurales que se construyen sobre este grupo y su desventaja. A su vez, esta discusión nos posibilitará tratar el concepto de discapacidad de la CDPD-ONU y las formas intermedias de aproximarse a este fenómeno, como la del realismo crítico y el enfoque de la neurodiversidad, exposición que contribuirá a superar malentendidos y reduccionismos que pudieran esencializar atributos de este grupo social. Desde luego, no es nuestra intención hacer una reconstrucción historiográfica profunda de la diversidad de modelos y submodelos teóricos que implican ${ }^{46}$, pero sí dar

\footnotetext{
44 Véanse, por ejemplo, VICTORIA (2013); PALAcIOs (2008). En ese mismo sentido, la Corte Interamericana de Derecho Humanos (Corte IDH) también declaró su adhesión a este modelo social en el Caso Furlán y familiares vs. Argentina. Excepciones preliminares, fondo, reparaciones y costas. Sentencia de 31 de agosto de 2012, párrafo 133. En otro momento, incluso la Corte IDH expandió su aplicación a casos que involucren a personas con VIH. Véase Corte IDH. Caso Gonzales Lluy y otros vs. Ecuador. Excepciones preliminares, fondo, reparaciones y costas. Sentencia de 1 de septiembre de 2015, párrafos 236-238.

45 Atienza (2016); Alemany (2018).

46 No trataremos en este artículo, por escapar de su objetivo, las perspectivas post estructurales, culturales o críticas, que impugnan fuertemente el razonamiento binario construido bajo el término discapacidad, en algunos casos bajo la influencia de las teorías queer, planteando modos abiertos de comprender este fenómeno y enfocándose en conceptualizar la discapacidad como discurso. Sobre este punto, véanse Vehmas y Watson (2013); Goodley et al. (2019); ShaKespeare (2014), pp. 47-71. Cabe anotar que estas perspectivas parten de lo elaborado tras el modelo social, por lo que hay quienes subsumen tales vertientes al construccionismo social, como Brown
} 
una presentación útil de las complejidades que subyacen al concepto de discapacidad mental, de cara a la comprensión y análisis de la jurisprudencia constitucional que realizaremos posteriormente.

\subsection{La discapacidad como patología}

La aproximación conceptual que mayor influencia ha tenido en las esferas social y política sin duda fue la que proporcionó inicialmente la profesión médica. Bajo la matriz conceptual que inauguró el estudio médico de los problemas mentales, comprender la discapacidad era tratar con un déficit individual o, en sus términos, con una patología ${ }^{47}$. El arraigo de esta perspectiva ha sido explicado vía metáforas, como la de la sociedad biomedicalizada ${ }^{48}$, que expresa la legitimidad cultural que ostenta la profesión médica sobre las tareas relativas al cuerpo humano ${ }^{49}$, su "poder discursivo privilegiado"50 que permite medicalizar distintas cuestiones, como ocurrió con las "anormalidades psicológicas" del siglo XIX ${ }^{51}$.

Desde luego, el Derecho no ha estado ajeno de esta influencia de parte de los profesionales de la medicina ${ }^{52}$. El estatuto jurídico de la persona con discapacidad mental es una muestra clara del nivel de influencia que ha tenido su conocimiento ${ }^{53}$, pues presupone que una persona haya

(1995), p. 36.

47 Fincham y Forbes (2019), p. 346; Palacios (2008), pp. 80-81; Baresford (2002), pp. 582-583. 48 Conrad (2007); Clarke et al. (2003); Ortega (2009), p. 426.

49 Аввотт (1988), p. 98.

50 THOMAS Y MILLIGAN (2017), p. 123.

51 Rogers Y PILGRIM (2005), p. 144.

52 SCHACHT (1992), p. 217; BRown (1995), p. 39. Naturalmente, la interacción entre el campo médico y jurídico no está exenta de tensiones (véase Rogers y PILGRIM (2005), pp. 192-211), que derivan en algunos casos en litigios, siendo ilustrativo de esto una reciente sentencia de la Corte Constitucional colombiana (Sentencia T-563/19 de 20 de noviembre de 2019). En ocasión a este caso, en el cual se demandaba que el sistema de salud pública colombiano brindara tratamiento a favor de unos niños con discapacidad mental, se discutió la línea que divide una patología y "manifestaciones de problemas estructurales de orden social, cultural, económico y político", pues muchos de los tratamientos solicitados se basaban en categorías médicas controvertidas, como el trastorno de aprendizaje, que conferían un alto nivel de discrecionalidad a los médicos. Así, la Corte estableció como pauta, entre otras, que "los profesionales de la salud deben evitar el sobre-diagnóstico y la patologización artificial de los menores de edad", además de promover la participación de estos menores con discapacidad mental en la toma de decisiones.

53 Areheart (2011), pp. 377-385. 
sido diagnosticada con una categoría profesional médica determinada que, bajo una aproximación neo-kraepeliniana ${ }^{54}$, serían definidas como patologías $^{55}$. La demencia, el Tay-Sachs, el síndrome de Down, el síndrome de Asperger son ejemplos de categorías diagnósticas que fueron desarrolladas por las profesiones médicas en base a una serie de descripciones o síntomas, por lo general, de origen genético o neurológico ${ }^{56}$, aunque en algunos sea difícil determinarlo como ocurre con el autismo ${ }^{57}$. Justamente, por haber sido desarrolladas estas categorías bajo este sistema de conocimiento, fueron ubicadas binariamente en el lado opuesto de lo conceptuado como normal, apropiado o saludable ${ }^{58}$.

En síntesis, este esquema inicial de la profesión médica llevó a que la discapacidad mental fuera entendida como la consecuencia de una de estas categorías diagnósticas ${ }^{59}$ que comparten ser la representación de un desvío de la habilidad de tener "pensamientos, razonamientos, sentimientos, aptitudes y acciones normales"60. Esta falta de ajuste a la normalidad, a lo saludable, es asociada por lo general con la falta de "la capacidad para adaptarse y gobernarse", lo que impacta en el bienestar subjetivo ${ }^{61}$. Esta condición fue vista entonces como una afectación en sí al bienestar individual, al asumir la pérdida de autonomía del sujeto y su

54 Double (2002), pp. 902-903.

55 La psiquiatría, como rama de la medicina encargada de esta tarea profesional, es la que asumió la existencia de enfermedades mentales, las cuales clasificaron, siendo el Diagnostic and Statistical Manual of Mental Disorders (DSM) el manual más relevante que detalla este sistema clasificatorio sobre la salud mental (CLARK et al. (2017)), elaborado para fines de utilidad clínica y con un valor heurístico (Hyman (2010), pp. 156, 160), pero sin estar exentos de críticas por su posible conexión con la industria farmacéutica (véanse AREHEART (2011), pp. 366-367; SCHACHT (1992), pp. 219-220). Sin embargo, otras profesiones han tenido otras aproximaciones hacia esta tarea y han disputado la jurisdicción cultural de la profesión médica, como la psicología o el psicoanálisis. Para el ilustrativo caso estadounidense, véase Аввотт (1988), pp. 289-314.

56 Katz y LazCANo-Ponce (2007); Hacking (1999), p. 117. Ciertamente este aspecto ha sido disputado en muchas ocasiones. Los psicoanalistas pueden asumir un origen estrictamente psíquico (véase Rogers y PILGRIM (2005), p. 5), mientras otros apuntan a un origen social, denominándolas enfermedades psicosociales. Para un análisis crítico de estas posiciones, véase VARGAS y LóPEZ (2011), pp. 591-592.

57 Hyman (2010), pp. 161-162; Keen et al. (2010), p. 274.

58 Baresford (2002), p. 582; Rogers y Pilgrim (2005), p. 125; Double (2002), p. 903.

59 AREHEART (2011), pp. 362-363.

60 RADDEN (2019).

61 HUBER et al. (2011), p. 2. 
consecuente dependencia y rol pasivo ante los posibles tratamientos ${ }^{62}$.

Comprendida solo como la consecuencia de una patología, el desafío de las sociedades respecto a la población con alguna discapacidad mental no encontraba mayor horizonte que el de la atención individual, pues era un asunto estrictamente clínico ${ }^{63}$. Si este colectivo experimentaba alguna desventaja social, esta se explicaba solo en su situación mental. Así, la medicalización y, en los casos más graves, el internamiento forzoso eran las respuestas más idóneas, en la búsqueda de rehabilitarlos como individuos antes de que vuelvan a integrarse a la sociedad, si acaso era posible ${ }^{64}$. Esta conceptualización de discapacidad, y sus consecuencias, fue asumida dentro de las políticas de Estado y es lo que formó el modelo médico o psiquiátrico. Lo cierto es que esta política de Estado aunada a la raigambre cultural que concebía negativamente las mentes no ideales ${ }^{65}$, acrecentó la experiencia opresiva que significaba ser diagnosticado con una enfermedad mental, que los concebía como seres incompletos o inadecuados ante el ideal biológico asumido ${ }^{66}$.

Dada esta desatención a las cuestiones sociales y, sobre todo, a la experiencia de discriminación que fomentó, este modelo médico fue cuestionado tanto por distintos movimientos como por las Ciencias Sociales ${ }^{67}$. Lo anterior llevó a que incluso el propio entendimiento de la medicina sobre la discapacidad fuera repensado y abierto a las cuestiones sociales, como se ve reflejado, por ejemplo, en el modelo biopsicosocial que propone la Clasificación Internacional del Funcionamiento, de la Discapacidad y de la Salud ${ }^{68}$.

\subsection{La discapacidad como constructo social}

Los movimientos sociales que canalizaban la experiencia de discri-

62 Goodley et al. (2019), p. 987; SHILDRICK (2012), p. 36.

63 Gómez y Castillo (2016), pp. 188-189; Palacios (2008), pp. 97-98; Victoria (2013), p. 824.

64 Rogers y PILGRIM (2005), p. 197; Palacios (2008), pp. 90-97.

65 WALMSLEY (2020).

66 SHILDRICK (2012), p. 35; Hughes (2012), pp. 72-73.

67 SloRAch (2014); SHAKESPEARE (2014), pp. 12-14; SHILdRICK (2012), p. 35.

68 Organización Mundial de la Salud (2001); Palmer y Harley (2012), pp. 358-359. 
minación de las personas con discapacidad encontraron en el modelo social propuesto por Mike Oliver una respuesta al modelo médico que dominaba en el espacio público, así como todo un nuevo esquema para entender qué era la discapacidad ${ }^{69}$. Esta respuesta social aglutinó tanto a las personas con discapacidad física y mental bajo la premisa que la discapacidad era sinónimo de opresión, siendo necesario su tratamiento no como una cuestión médica, sino de derechos fundamentales, de acciones públicas que permitan remover estas barreras socialmente construidas y externas, por supuesto, al individuo ${ }^{70}$.

La discapacidad fue redefinida semánticamente para dejar de estar asociada con la heterogeneidad de déficits individuales, y asumir una causa ubicada en la estructura de la sociedad ${ }^{71}$. En su versión más ortodoxa, este esquema deriva en una aproximación fundamentalmente materialista, al definir la discapacidad como producto de las relaciones sociales opresivas, jerárquicas hacia este grupo, es decir, un constructo social ${ }^{72}$. Tratar estas barreras implicaba romper, entonces, con las "estructuras normativas de la sociedad dominante"73 y asumir políticas igualitarias que permitieran compensar las desventajas estructurales que estas causaban, tanto en las esferas educativas, laborales, sanitarias, entre otras, como también en el ámbito cultural, de las actitudes hacia estas personas ${ }^{74}$. Se conseguiría, así, una igualdad de oportunidades de superarse tales barreras, lo que implicaría, a su vez, la superación de la experiencia de discapacidad ${ }^{75}$.

En este orden de ideas, la discapacidad fue disociada del concepto de déficit, similar a la separación entre sexo y género, llegando incluso a afirmarse en algunos casos que no tenían conexión alguna y que en realidad era una imposición que generaba una experiencia de exclusión ${ }^{76}$.

69 Areheart (2011), pp. 350-351; SLoRAch (2014), pp. 165-166.

70 SHAKESPEARE (2014), p. 29; Baresford (2002), p. 583.

71 PALACIOS (2008), p. 23; SHILDRICK (2012), p. 35.

72 SHAKESPEARE (2014), pp. 21-23; VehMAS y Watson (2013), p. 647.

73 SHILDRICK (2012), p. 35.

74 Vehmas y Watson (2013), p. 643; Rogers y PILgRim (2005), pp. 39-40; SHILdRICk (2012), p. 36.

75 SHAKESPEARE (2014), p. 106.

76 Areheart (2011), pp. 350-351; Shakespeare (2014), pp. 12-14. 
Así, se desbiologizó y, por tanto, se desmedicalizó la discapacidad, a fin de que las categorías médicas no definan a las personas que conforman este grupo social. El concepto de déficit o deficiencia asumiría la carga patológica que en el anterior esquema lo tenía el término discapacidad.

Este quiebre semántico fue logrado, a su vez, por los cuestionamientos a la conceptualización misma de las enfermedades, al evidenciar las condiciones espacio-temporales que las formaban y, en un grado extremo, de señalar que eran construcciones sociales contingentes y no neutrales ${ }^{77}$. Ello llevó, en algunos casos, a cuestionar directamente el conocimiento experto de las profesiones médicas ${ }^{78}$ e iniciar movimientos en contra de la medicalización y, sobre todo, en contra de las políticas de segregación y de eugenesia contra esta población que, además del internamiento forzoso, llevó a ser articulada con instituciones jurídicas que implicaban no poder ejercer sus derechos directamente ${ }^{79}$.

Ahora bien, tal conceptualización no necesariamente tiene una identidad con el modelo social de discapacidad. Esta definición que deriva de un construccionismo social ortodoxo que hemos expuesto es una entre varias formas de concebir este fenómeno ${ }^{80}$. Lo cierto es que la fundamentación del modelo social desde este construccionismo social no ha quedado exenta de críticas. Entre otras cuestiones, se objetó la circularidad que adquiere el concepto de discapacidad, las limitaciones del diseño universal, la no representación adecuada de la experiencia de las personas con discapacidad mental, ser opresiva culturalmente por persistir en una lógica binaria y la prescindencia de los conocimientos médicos ${ }^{81}$.

77 ConRad (2007), p. 7; Brown (1995); SHAKESPEARE (2014), pp. 58-59.

78 Se cuestionó si la medicina era autosuficiente para proveer bienestar a esta población. Esto se refleja en la aparición de lógicas que compiten con el enfoque de salud de los psiquiatras, como el de cuidado, más holísticas y comprehensivas de otras profesiones. Sobre el particular, véase FINCHAM Y FORBES (2019).

79 Palacios (2008), pp. 165-167; Walmsley (2020), pp. 97-99.

80 Dentro de la corriente teórica que edificó el modelo social hay varias alternativas, como el relacional que elaboró Carol Thomas, que toma en consideración un elemento individual, como lo son los "efectos psico-emocionales" de la discapacidad. Para una perspectiva crítica de esta aproximación, véase SHAKESPEARE (2014), pp. 75-78. Para ver las otras vertientes del modelo social, véase TRAUSTADÓtTIR (2009), pp. 9-15.

81 Vehmas y Watson (2013); Shakespeare (2014), pp. 11-46; Palmer y Harley (2012), p. 358. 


\subsection{La discapacidad en la CDPD-ONU y la propuesta interaccional del realismo crítico}

El ejercicio de exponer, de manera sintética, dos visiones extremas sobre cómo concebir la discapacidad mental nos permitió reflejar una tensión intrínseca en el tratamiento de las personas que conforman este colectivo: entre lo individual y lo estructural. Si bien la narrativa de estos estudios presenta a la concepción social como una superación de la anterior, una reciente apología hacia la perspectiva que asocia la discapacidad con enfermedad es provista por Atienza y Alemany ${ }^{82}$, críticas que nos invita a revisar ambos conceptos, a fin de aproximarnos a la posición de la CDPD-ONU y, luego, a exponer una posición intermedia elaborada por Tom Shakespeare, a fin de obtener un marco referencial adecuado para atender la experiencia de desventaja de este grupo.

Por un lado, Atienza parte de objetivizar la realidad de las enfermedades, fundada en un texto de Bunge ${ }^{83}$, al negar la existencia de una dimensión subjetiva en la conceptualización de discapacidad, tal como también ocurriría en el planteamiento de una enfermedad ${ }^{84}$. Se vale para fundar esta postura del ejemplo de la demencia senil85. Matizando esta postura, Alemany no niega que la medicina pueda añadir elementos de subjetividad al momento de analizar un fenómeno, pero luego agrega

82 Atienza (2017); Alemany (2018).

83 BUNGE (2009), pp. 159-161.

84 Atienza (2017), p. 265. En el caso de Bunge, puede deducirse de su breve exposición que él parte enteramente de enfermedades con una causa biológica no discutida, por lo que no problematiza los datos que proporciona la historia de las enfermedades, como el hecho de haberse considerado a la homosexualidad como una patología (véanse ConRAD (2007), pp. 97-113; AlemANY (2018), p. 216) o que las clasificaciones diagnósticas de enfermedades mentales, como el DSM, sean consideradas por sus propias comunidades profesionales como documentos vivos (véase Hyman (2010), p. 166). Para una perspectiva ponderada entre el realismo y el construccionismo, véase HACKING (1999), pp. 100-124.

85 Sobre este caso, el estudio de BoyLE (2014) muestra cómo incluso las personas con demencia senil conservan la capacidad de decidir sobre varios aspectos de su vida, no necesariamente con palabras, sino en formas creativas o prácticas, que requieren interpretación y asistencia, pero no una sustitución en sí. Para un estudio meta-etnográfico que condensa los hallazgos sobre las experiencias de las personas con demencia en la toma de decisiones, véase Bosco et al. (2018). Por su parte, SERIES (2015) trata directamente el asunto de la capacidad jurídica, mostrando un debate que, ciertamente, se inclina a no sustituir la voluntad. 
que la discapacidad es un mal que debe ser combatido ${ }^{86}$. Lo cierto es que ambos asumen que las personas con discapacidad no pueden valerse por sí mismas y, por ello, esta sería la causa objetiva y razonable para recibir un trato diferenciado ${ }^{87}$. Alemany argumenta a favor de considerar análogas las situaciones de las personas con discapacidad mental con la de los menores de edad, en vez que con el género y la raza ${ }^{88}$. La crítica apunta, en última instancia, a cuestionar las bases de la CDPD-ONU y su inclinación declarada por el construccionismo social ${ }^{89}$.

Sin entrar al debate sobre la capacidad jurídica de las personas con discapacidad, tanto Atienza como Alemany esencializan como característica de las personas con discapacidad mental la falta de discernimiento, sin tomar en cuenta la heterogeneidad cognitiva presente en este grupo social, al tratar de desvirtuar el modelo social asumido en la CDPD-ONU. Pero el principal malentendido se da, desde nuestro punto de vista, al asociar el construccionismo social más ortodoxo con el modelo social tras la CDPD-ONU, sin considerar la permeabilidad existente en la propia definición de discapacidad que nos brinda este tratado, tanto en el parágrafo (e) del Preámbulo como en el segundo párrafo del artículo $1^{90}$. Sobre esta definición resaltamos dos cuestiones que permiten rebatir la asociación de Atienza y Alemany.

En primer lugar, y tal como señala Lord, el Preámbulo expresamente denota la naturaleza temporal y matizada de la concepción de discapacidad al mencionar que la discapacidad "es un concepto que evoluciona", por lo que es claro que no se pretendía brindar "una comprensión fija y estática de la discapacidad", a fin de que no resulte en "una restricción

86 Alemany (2018), p. 216.

87 Alemany (2018), p. 217; Atienza (2017), pp. 264-265.

88 Alemany (2018), p. 204.

89 Atienza (2017), p. 265; Alemany (2018), pp. 214-218.

90 El primero señala que: "la discapacidad es un concepto que evoluciona y que resulta de la interacción entre las personas con deficiencias y las barreras debidas a la actitud y al entorno que evitan su participación plena y efectiva en la sociedad, en igualdad de condiciones con las demás". Luego, en el artículo 1, define que "Las personas con discapacidad incluyen a aquellas que tengan deficiencias físicas, mentales, intelectuales o sensoriales a largo plazo que, al interactuar con diversas barreras, puedan impedir su participación plena y efectiva en la sociedad, en igualdad de condiciones con las demás". 
para la realización de los objetivos de la Convención"91. De esto sigue la segunda cuestión, que es reconocer que materialmente la CDPD-ONU "va más allá del modelo social" a la luz de lo que regula, siendo más apropiado el término $\mathrm{MDDH}^{92}$. Y es que si leemos la definición de discapacidad, vemos que incluye a las deficiencias, punto que no sería aceptable para un construccionista social rígido. Si bien es plausible interpretar la mención a las deficiencias de tal modo que se reduzcan a ser meramente constructos sociales externos al individuo, creemos que en los propios artículos de la CDPD-ONU se descarta esta clase de interpretaciones teóricamente ortodoxas.

Compartimos la preocupación acerca de que tal línea extrema de pensamiento llevaría a soslayar una consideración individual y, por tanto, dejar de lado cualquier clase de medicalización por tomarla como una amenaza a la diversidad que encarna este grupo social ${ }^{93}$. Sería incompatible con financiar investigación médica preventiva en algunas discapacidades mentales de origen contextual y con una prevalencia en personas en situación de pobreza, por mencionar un ejemplo ${ }^{94}$. Pero, como señalábamos, tales preocupaciones no son observables en la CDPD-ONU, pues en su artículo 25 expresamente reconoce la obligación de los Estado de brindar las prestaciones de salud que necesite una persona "como consecuencia de la discapacidad" y que permitan "prevenir y reducir al máximo la aparición de nuevas discapacidades". De este modo, sustentar la CDPD-ONU solo en el modelo social "sería ignorar el lenguaje que emplea"95.

Por lo anterior, hay quienes incluso han señalado que la definición de

91 LORD (2018), pp. 13-14.

92 KaKOULLIS e IKEHARA (2018), p. 38.

93 Kapp et al. (2012), p. 60; SHAKESPEARE (2014), pp. 138-140.

94 Katz y LazCANo-Ponce (2008), pp. 134-135.

95 KAKOULLIS e IKEHARA (2018), p. 54. No debe perderse de vista que el propio modelo social no sería incluso incompatible con lo expuesto en la CDPD-ONU, si consideramos el parecer pragmático de OLIVER y BARNES (2012), p. 7, impulsores de este modelo, respecto a que "[e]l modelo social es una herramienta que debe ser utilizada para producir cambios en la sociedad y no es y nunca fue una teoría social". 
la CDPD-ONU es más médica que social ${ }^{96}$, dada la cercanía de su definición de discapacidad a la que provee el modelo biopsicosocial de la Clasificación Internacional del Funcionamiento, de la Discapacidad y de la Salud de la Organización Mundial de la Salud ${ }^{97}$, el cual expresamente sintetiza el modelo médico y social ${ }^{98}$. Y es que, como señalábamos antes, el MDDH de la CDPD-ONU no lleva al extremo los postulados del construccionismo social, poniéndose, en cambio, en una posición que pragmáticamente procura establecer una serie de reivindicaciones, tanto individuales como estructurales, para las personas con discapacidad.

Lo individual es, pues, un componente fundamental en la experiencia de las personas con discapacidad mental, que no puede ser dejado de lado por un enfoque estructural que quiera tratar las desventajas de este grupo social, bajo el riesgo de ignorar "el dolor que las personas pueden experimentar" a raíz de estas deficiencias ${ }^{99}$. Pero la inclusión de la dimensión individual no significa reproducir nuevamente la perspectiva del modelo médico, ya que este elemento se interrelaciona, a su vez, con lo estructural. Una clara expresión de este cambio lo encontramos en el ejemplo del artículo 25 de la CDPD-ONU presentado antes. Justamente, dicho artículo, al regular las prestaciones de salud, incluye la participación de las personas con discapacidad para que "definan y redefinan los términos de su propio compromiso con la atención médica moderna" y que primen, en última instancia, "sus necesidades de salud"100. Tal elemento participativo, desde luego, no sería factible bajo un modelo propiamente médico.

Esta visión pragmática no debe tampoco llevarnos a declarar que hay una orfandad teórica que pueda sustentar la CDPD-ONU, pues, en realidad, las aproximaciones sobre la discapacidad ciertamente no están

96 BiCKENBACH (2009), pp. 1120-1121; LeONARDI et al. (2006), p. 1220.

97 Esta definición señala que la "Discapacidad es un término genérico que incluye déficits, limitaciones en la actividad y restricciones en la participación. Indica los aspectos negativos de la interacción entre un individuo (con una "condición de salud") y sus factores contextuales (factores ambientales y personales)". ORganización Mundial de LA Salud (2001), p. 227.

98 Organización Mundial de la Salud (2001), p. 22.

99 KaKOULLIS e IKEHARA (2018), p. 37.

100 WeLLeR (2018), p. 710. 
polarizadas entre quienes abogan por una visión plenamente médica, individual frente a quienes postulan que el único campo de acción posible es el estructural. Una de estas es la posición del realismo crítico, elaborada por Tom Shakespeare, que, fuera del construccionismo social, provee un marco analítico más adecuado para aproximarse al MDDH de la CDPD-ONU. Este asume ambas dimensiones de la cuestión de la discapacidad, al señalar que esta se construye a partir de la interacción de las deficiencias individuales con aspectos estructurales que derivan en la experiencia de discriminación. En sus propios términos, "las personas están discapacitadas por la sociedad y por sus cuerpos"101, pues "la realidad es que (...) se ven afectadas por problemas físicos y psicológicos, así como por barreras externas"102. La existencia de un substrato objetivo, biológico es dada por real y constituye parte de la experiencia de la discapacidad, que debe ser considerada para lograr el desarrollo de las capacidades de estas personas ${ }^{103}$, lo que demanda "entrenamiento o terapia para mejorar la autoestima; intervención médica para restaurar el funcionamiento o reducir el dolor; ayudas y adaptaciones; eliminación de barreras; lucha contra la discriminación y cambio de actitud; mejores beneficios y servicios" 104 . No olvidemos que tener una determinada discapacidad mental puede hacer que uno este predispuesto a desarrollar otras discapacidades o a tener defectos físicos que impidan el desarrollo de capacidades $^{105}$. Por ello, el conocimiento médico o, en general, científico puede ayudar al desarrollo individual y a la inclusión de este grupo en la sociedad, sin soslayar que también se requiere implementar políticas sociales. El problema de la discapacidad mental es, pues, multidimensional.

101 SHAKESPEARE (2014), p. 75.

102 SHAKESPEARE (2014), p. 82.

103 Para SHAKESPEARE (2014), pp. 41-42, la remoción solo de las barreras sociales no hará que las deficiencias sean irrelevantes para la vida en sociedad, pues "las especificidades de las deficiencias también crean una desventaja que ningún arreglo social inclusivo puede mitigar". Por esto no quita que "(...) se necesita un proceso para identificar a las personas que ahora están en peligro de exclusión, y apoyarlas para maximizar sus habilidades, y luego ayudarlas a hacer una contribución productiva dentro de sus capacidades, y a vivir una existencia plena y valorada". SHAKESPEARE (2014), p. 62.

104 SHAKESPEARE (2014), p. 83.

105 Nussbaum (2007), p. 194. 


\subsection{La neurodiversidad como concepto disruptivo al de discapacidad mental}

Pero aquí entra otro nivel de complejidad, ya que en ciertos casos las categorías diagnósticas han fomentado el desarrollo de identidades que encuentran paralelismo con la cuestión del género o la raza ${ }^{106}$. Esto ocurre dado que tras el concepto de discapacidad mental se aglutinan una heterogeneidad de etiquetas que no necesariamente comparten ser realidades semejantes y que, más bien, requieren un reconocimiento que los diferencie ${ }^{107}$. Mientras que hay deficiencias que razonablemente uno buscaría evitar ${ }^{108}$, como la demencia originada por una bacteria ${ }^{109}$, hay variaciones humanas no desadaptativas que serían, en cambio, expresión de una diversidad cognitiva y no de una deficiencia ${ }^{110}$. Esto último alude a la neurodiversidad, término que se "refiere a un espectro de funciones cognitivas, lingüísticas y de aprendizaje, y condiciones neurobiológicas de inicio temprano que afectan la capacidad de comprensión social, interacción social, aprendizaje y comunicación pragmática y semántica del individuo"111. Estas diferencias serían "(...) una parte inherente y valiosa del rango de variación humana, en lugar de una forma patológica de

106 Kapp et al. (2012), p. 61; CARMACK (2014), pp. 469-471.

107 Sobre este punto, concordamos con Alemany al entender que la discapacidad presenta una heterogeneidad interna, cuestión que no necesariamente se da en el caso del género o la raza (2018), pp. 213-214. No obstante, su análisis se ve limitado al esencializar las características de las personas con discapacidad mental y, justamente, no realizar el ejercicio de distinción en este grupo desaventajado.

108 Como señalan VeHMAS y WATSON, “(...) una razón por la cual las personas generalmente prefieren no tener deficiencias es ética; ellos creen que algunas deficiencias pueden en sí mismas evitar que las personas actúen y se muevan como deseen, que realicen actividades valiosas o que les vaya bien en general" (2014), p. 641.

109 HENS et al. (2009).

110 Gyngell y Douglas (2016), pp. 9-10; Carmack (2014), pp. 465-466; Fenton y Krahn (2007), p. 1.

111 LolLINI (2018), p. 74. Serían neurodiversos no solo quienes tienen autismo de funcionamiento alto (síndrome de Asperger) y bajo, sino también quienes presentan "trastorno por déficit de atención e hiperactividad, trastorno bipolar, dispraxia, dislexia, epilepsia y síndrome de Tourette", de acuerdo a FENTON y KRAHN (2007), p. 1. No obstante, también hay concepciones más restrictivas que asocian la neurodiversidad a solo "los individuos con trastornos del neurodesarrollo de alto funcionamiento como el trastorno del espectro autista". LoLLINI (2018), p. 71. 
diferencia"112, que deben ser comprendidas "en términos de neurología innata (...) quizás respaldado por causas genéticas"113.

Como es notorio, esta aproximación se teje a partir de aspectos biológicos y de la apropiación semántica de las categorías diagnósticas para convertirlas en una cuestión de diversidad y, por tanto, de orgullo y celebración ${ }^{114}$. Es por esto que el movimiento de neurodiversidad despertó temores a que sea una vuelta al modelo médico ${ }^{115}$, pues, como vimos, el construccionismo social parte de desbiologizar la experiencia de la discapacidad y posicionarla de manera externa a la persona. No obstante, esta preocupación no tomaba en cuenta que la consecuencia de conceptualizar esta condición como una diversidad cognitiva es justamente el rechazo a la medicalización de su condición o la búsqueda de una cura $^{116}$, pero sin descartar intervenciones individuales que les permita su mejor desarrollo, ya que "la condición puede tener algunos efectos incapacitantes" que afectan a la persona y a su familia ${ }^{117}$. Un modelo social rígido se ve, a su vez, interpelado ante esta última posición de los propios movimientos de neurodiversidad, que abogan por reconocer que hay una "interrelación entre los desafíos internos y sociales"118. La neurodiversidad, en suma, supera también la pugna teórica entre lo individual y lo estructural, siendo el punto de conexión entre ambos la promoción del bienestar de esta población ${ }^{119}$ y alcanzar su "independencia, inclusión y

112 DYCK Y RUSSELL (2020), p. 170.

113 DYCK y RusselL (2020), p. 175. Estas variaciones son valiosas para la sociedad, no solo por constituir una diversidad en sí, sino porque la enriquecen con criterios que individuos neurotípicos difícilmente podrían desarrollar. Por dar un ejemplo, las personas con síndrome de Asperger agregan "una perspectiva única sobre los problemas y los alienta a desarrollar heurísticas diferentes (y a menudo altamente efectivas) para resolver problemas". GYNGELL y DougLAs (2016), p. 11.

114 Kapp et al. (2012), p. 60; Dyck y Russell (2020), p. 171.

115 Ortega (2009), p. 441; Degener (2016), p. 9.

116 Fenton y Krahn (2007), p. 2; Kapp et al. (2012), p. 66. Como anotan Dyck y Russell (2020), pp. 177-179, es interesante apreciar el paralelismo que hay entre el movimiento de neurodiversidad y el transgénero, pues este último articuló sus demandas desde la categoría diagnóstica del trastorno de identidad de género, que luego fue desmedicalizada.

117 O’ReILLY et al. (2020), p. 152; LoLLINI (2018), p. 78.

118 Kapp et al. (2012), p. 68.

119 O'ReILLY et al. (2020), p. 152. 
participación en la sociedad"120.

Estas demandas de los movimientos de neurodiversidad permitieron acuñar el término de neuroigualdad, que expresa la exigencia de "igualdad de oportunidades, tratamiento y consideración para aquellos que son neurológicamente diferentes"121, lo cual pasa, entre otras consideraciones individuales, por "crear comunidades más inclusivas fomentando el cambio social y las adaptaciones"122. Ahora bien, la inclusión de esta nueva minoría, al construirse bajo una identidad diferente al de discapacidad ${ }^{123}$, plantea al menos dos retos iniciales. El primero es su reconocimiento, pues son invisibilizados al ser subsumidos dentro del grupo desaventajado de personas con discapacidad mental, que es un marcador social que no refleja la diferencia central de este grupo, que es la diversidad cognitiva. Este es un aspecto pendiente, pues, como hemos visto, efectivamente hay bases que justifican una distinción de este grupo social respecto al de las personas con discapacidad y que lleven, por ejemplo, a tratarlo como un motivo prohibido de discriminación diferenciado. Si bien son dos identidades que pueden intersectarse, la consideración sobre si tienen o no una deficiencia es lo que marca la diferencia de categorización. El segundo reto es, considerando su subsunción en este grupo, si el MDDH de la CDPD-ONU es un canal apropiado para la consecución de los objetivos individuales y sociales del movimiento de neurodiversidad. Sobre este punto, la respuesta ha sido afirmativa, pues este provee un marco tuitivo lo suficientemente flexible para permitirles las provisiones sociales necesarias para tanto su adaptación como el de la sociedad ${ }^{124}$. Como Lollini indica, el artículo 3 de la CDPD-ONU condensa los principios que reivindican los movimientos de neurodiversidad ${ }^{125}$, además de

120 LoluINI (2018), p. 73. Uno de los objetivos que más acentúa este movimiento es el logro de una vida independiente de las personas neurodiversas. Esta demanda, como apuntan Fenton y Krahn, no se desvirtúa por el hecho que muchos neurodivergentes requieran "cuidados especiales y apoyo social", pues esta interdependencia es su forma de independencia (2007, p. 4).

121 Fenton y KRAHn (2007), p. 1.

122 LolLINI (2018), p. 79.

123 LoLLINI (2018), pp. 91-93.

124 Kapp et al. (2012), p. 67.

125 LolLINI (2018), p. 90. 
reconocer el "derecho a vivir de forma independiente y a ser incluido en la comunidad" en su artículo 19, que es una de las demandas centrales de esta nueva minoría.

En resumen, y tal como la CDPD-ONU reconoce, la discapacidad "es un concepto que evoluciona" y debe hacerlo a la luz de las identidades y realidades heterogéneas que alberga. Debe estar abierto a su revisión a la luz de la aparición de estas nuevas identidades que reclaman un igual reconocimiento. Es por ello que esencializar a los grupos desaventajados es un peligro para cualquier enfoque igualitario que parta del análisis de colectivos. Lo es también partir de contradicciones, muchas veces teóricas, que no reflejan sus necesidades. Tanto lo individual como lo estructural están en el centro de la experiencia de la discapacidad mental.

\section{La multidimensionalidad de la igualdad en la CDPD-ONU}

La segunda disrupción que trataremos es respecto al modelo de igualdad que fundamenta la CDPD-ONU, modelo que, siendo este el primer tratado de derechos humanos del siglo XXI como apunta Arnardóttir, es marcado por su enfoque asimétrico de corrección de las desventajas ${ }^{126}$. Este enfoque asimétrico de igualdad, marcadamente contextual, es el resultado de una serie de desarrollos que trajo el feminismo y el construccionismo social, los cuales desestabilizaron los cimientos de la tradición de la igualdad como no-discriminación, al evidenciar, por ejemplo, los sesgos del agente comparador ${ }^{127}$. De igual modo, estos movimientos cuestionaron que la igualdad sustantiva tradicional tuviera un carácter meramente relacional, por lo que plantearon, como respuesta, un enfoque basado en la remoción de barreras construidas socialmente, que permitió desplazar la discusión hacia las "consecuencias estructurales o sistémicas del género"128.

Pero la CDPD-ONU no solo codifica esta nueva tendencia en materia de igualdad, sino que también se ubica en una discusión más amplia,

126 ARNARDÓtTIR (2009), p. 54.

127 FREDMAN (2011), p. 11.

128 ARNARDÓtTIR (2009), pp. 54-55. 
que Mégret denomina "pluralización de los derechos humanos", la cual se refiere al hecho de reconocer "las necesidades de grupos o categorías específicas dentro de la humanidad como dignas de una protección específica de los derechos humanos"129. Como este autor apunta de forma crítica, esta tendencia es, a la vez, disruptiva de la noción de universalidad de los derechos humanos, pues mostraría que los tratados vigentes en función de materias económicas, sociales y culturales fueron insuficientes para comprender y tratar estas diferencias humanas, incluso al invisibilizarlas, habiendo la necesidad de pasar a un "enfoque en función de la protección de grupos"130. Es por este motivo que la CDPD-ONU deviene en ser "uno de los intentos más importantes para corregir esa excesiva «unidad» de los derechos humanos, en un contexto particular", que permita reflejar la experiencia de las personas con discapacidad ${ }^{131}$.

Habiendo ya tratado en qué consiste esta diferencia jurídicamente relevante, a propósito de la discusión en cuanto al concepto de discapacidad mental, ahora nos detendremos en esta propuesta global de igualdad. Para tales efectos, primero discutiremos el modelo de igualdad inclusiva de la CDPD-ONU, que implicará tanto atender la interpretación del Comité sobre los Derechos de las Personas con Discapacidad (el Comité en adelante) como su compatibilidad con el modelo de igualdad transformativa de Sandra Fredman. Luego, desglosaremos este modelo en las cuatros dimensiones que componen la igualdad, para finalizar con un análisis crítico respecto a la posible articulación entre la formulación de la igualdad real de oportunidades del Tribunal Constitucional peruano con este modelo de la CDPD-ONU.

\subsection{El modelo de igualdad inclusiva y la influencia de Sandra Fredman}

Conforme a sus atribuciones declaradas en el artículo 39 de la CDPD-

129 MÉGRET (2008), p. 495.

130 MÉGRET (2008), pp. 496-497.

131 MÉGRET (2008), p. 515. 
ONU, el Comité emitió una sexta observación de carácter general ${ }^{132}$ que encuadra el artículo 5 de la CDPD-ONU, sobre igualdad y no discriminación, y su relación con distintos artículos del tratado, bajo la propuesta teórica de Sandra Fredman, de igualdad transformativa, aunque denominándole igualdad inclusiva. Este modelo sustantivo de igualdad aporta claramente un entendimiento integral de la lógica de la CDPD-ONU desde una visión multidimensional.

Resulta importante aclarar, antes de proseguir con el análisis, si este encuadramiento propuesto es una mera observación no vinculante de parte del Comité o si esta observación general es una interpretación que vincula a los Estados parte de la CDPD-ONU. Al comentar los alcances de las observaciones generales, Treuthart da cuenta de la tendencia a considerar que los pronunciamientos de este Comité tienen una autoridad para indicar la manera cómo implementar la CDPD-ONU, a la cual contribuyen los propios Estados parte, pero sin llegar a entenderlos como jurídicamente vinculantes ${ }^{133}$. Más allá de las posibilidades de comprender las observaciones generales como una práctica ulterior de los Estados que permita incluirlos dentro de los cánones de interpretación de la CDPD-ONU, conforme al artículo 31 de la Convención de Viena ${ }^{134}$, lo cierto es que el planteamiento de este modelo de igualdad es consistente con lo regulado en la CDPD-ONU y aclara, a su vez, cómo implementar de manera articulada las obligaciones de los Estados a favor de las personas con discapacidad. Más aun, este modelo de igualdad condensa una serie de desarrollos anteriores que circulaban en el espectro de enfoques asimétricos de la igualdad, que parten de una realidad compuesta por grupos desaventajados. Es así que varios académicos ${ }^{135}$, incluyendo a la propia Fredman ${ }^{136}$, reconocen que tras la CDPD-ONU está un modelo de igualdad transformativa.

132 Comité sobre los Derechos de las Personas con Discapacidad (2018).

133 TREUTHART (2018), p. 1125.

134 TREUTHART (2018), pp. 1126-1127.

135 BRoderick (2015), pp. 382-384; Degener (2016), pp. 17-19; CoRsi (2018), pp. 141-142; WeLLER (2018), p. 710.

136 FREDMAN (2011), p. 98. 
No obstante, al explicitar que la CDPD-ONU parte de un modelo tetradimensional de igualdad, el Comité omite mencionar la clara influencia que recibió del modelo de igualdad transformativa de Sandra Fredman y, en cambio, la denomina como igualdad inclusiva. Más allá de que esta omisión pueda explicarse por la naturaleza de este documento, lo cierto es que en la elaboración de la observación hubo una intervención de la profesora de Oxford, junto con otras académicas, que sugirió al Comité adoptar el modelo multidimensional de igualdad transformativa, en vez de un enfoque basado en la igualdad de oportunidades ${ }^{137}$. Aquella propuesta fue finalmente incorporada en el contenido de la observación, aunque prefiriendo darle otra nomenclatura.

Ciertamente, cabe la crítica a la variación del término a inclusivo, pues puede reflejar un objetivo asimilacionista a favor de los grupos dominantes de la sociedad que no atiende "las condiciones estructurales que crean y perpetúan las desigualdades sistémicas", además de entenderse contrario al término de transformación, que supone "cambiar las relaciones de poder que mantienen el statu quo"138. Sin embargo, si consideramos el contexto tetradimensional en que se incluye el término inclusivo, convendremos en que resulta ser un sinónimo de transformativo. Es así que, independientemente de las etiquetas, el modelo de igualdad que plantea el Comité refleja el esfuerzo multidimensional de forjar una sociedad que permita la realización y el respeto de la diferencia, lo que supone transformar sus cimientos a través de ajustes y la remoción de barreras, como otras medidas encaminadas a este fin.

Por otro lado, mencionábamos antes que en un borrador de la observación el Comité propuso hacer central el término de igualdad de oportunidades, planteamiento que finalmente fue descartado. Tal decisión aparece justificada en el parágrafo 10 de la observación, al señalar el Comité que el enfoque de igualdad de oportunidades no resuelve el "dilema de la diferencia", al provenir de una matriz individualista que trata de arribar

137 FREDMAN et al. (2017), p. 5.

138 Albertyn (2007), p. 256. 
a un punto simétrico que no considera la diferencia ${ }^{139}$. Pero esta decisión también se entiende a raíz de la propia naturaleza de las disposiciones de la CDPD-ONU, pues hubieran asumido las limitaciones intrínsecas de acomodar las distintas dimensiones de igualdad a solo una de estas. Por ejemplo, si bien discriminar puede ser comprendido como una merma de las oportunidades de realización de las personas con discapacidad mental, su fundamento más cercano lo encontraremos en el respeto de la expresión digna que es la diferencia de estos grupos. Reducirlo a solo una dimensión genera una artificialidad que empobrece el análisis de una realidad compleja como la de los grupos desaventajados.

Dicho lo anterior, desarrollaremos a continuación las cuatro dimensiones que componen este modelo de igualdad, las cuales están relacionadas profundamente entre sí.

\subsubsection{Dimensión redistributiva}

De acuerdo al Comité, esta dimensión tiene como objetivo "afrontar las desventajas socioeconómicas" de las personas con discapacidad ${ }^{140}$. Fredman, en Discrimination Law, agrega que estas desventajas están asociadas con el "estatus" de los grupos bajo protección, al concentrarse allí desproporcionalmente, y que para romper con el ciclo que las causan no solo se debe atender la "mala redistribución de recursos y beneficios", sino "las estructuras que excluyan a las personas en la determinación de sus acciones", sean incluso sociales o culturales ${ }^{141}$. Bajo esta dimensión, las acciones afirmativas dejan de ser una excepción a la igualdad de trato y se convierten en medidas correctivas en función a la desventaja, que requieren ser complementadas con otras acciones que transformen las estructuras que las causan ${ }^{142}$.

En este contexto cobra sentido la referencia en el numeral 1 del artículo 5 de la CDPD-ONU respecto a que las personas con discapacidad

139 Comité sobre los Derechos de las Personas con Discapacidad (2018), p. 3; sobre el particular, véase BRODERICK (2015), pp. 71-73.

140 Comité sobre los Derechos de las Personas con Discapacidad (2018), p. 3.

141 FREDMAN (2011), pp. 26-27.

142 Arnardóttir (2009), p. 53; Broderick (2015), pp. 115-117, Fredman (2011), pp. 26-27. 
"son iguales en virtud de la ley". Este reconocimiento, de acuerdo al Comité, es un "concepto exclusivo" de la CDPD-ONU, que da el marco para consagrar el "derecho a utilizar la ley en beneficio personal"143. Esto presupone que los Estados parte hayan desarrollado medidas específicas a favor de este grupo y conforme las demás regulaciones de la propia CDPD-ONU ${ }^{144}$. Más aun, los Estados deben abstenerse de discriminar o imponer barreras a estas medidas correctivas de la desventaja ${ }^{145}$.

Pero, como se mencionó, estas medidas serían insuficientes si no fueran acompañadas por acciones transformadoras, que no son otra cuestión que garantizar "los derechos mínimos básicos, tales como educación, vivienda, salud, trabajo y seguridad social"146. Ahora bien, es cierto que estas acciones pueden ser también comprendidas bajo el punto de vista del logro de la igualdad sustantiva de oportunidades, lo cual llevaría a trasladar los cuestionamientos teóricos de la noción de oportunidad a la dimensión redistributiva ${ }^{147}$. No obstante, el contexto multidimensional en que se insertan estas acciones estructurales permite compensar esta concepción al interactuar con las otras dimensiones. Es así que una medida como fomentar en el ámbito educativo "una actitud de respeto a los derechos de las personas con discapacidad", de acuerdo al literal b, del parágrafo 2 del artículo de la CDPD-ONU, puede ser analizada como una medida redistributiva cultural que garantiza mejores oportunidades para este grupo desaventajado, pero siempre que lo perfilemos en interacción con la dimensión de reconocimiento, que demanda el respeto de la dignidad de las personas con discapacidad.

\subsubsection{Dimensión de reconocimiento}

El Comité establece que esta dimensión tiene un doble propósito: tanto "combatir el estigma, los estereotipos, los prejuicios y la violencia", como "reconocer la dignidad de los seres humanos y su interseccionali-

143 Comité sobre los Derechos de las Personas con Discapacidad (2018), p. 4.

144 CORSI (2018), p. 160.

145 Comité sobre los Derechos de las Personas con Discapacidad (2018), p. 4.

146 FREDMAN (2011), p. 98.

147 FREDMAN (2011), pp. 19, 27-28. 
dad"148. Fredman aborda ambos objetivos casi en los mismos términos ${ }^{149}$, salvo en la referencia que hace el Comité a la interseccionalidad de la experiencia humana, aunque, de por sí, es un tema que está implícito en esta dimensión.

El enfoque de reconocimiento considera, entonces, que el respeto de la dignidad implica que el Estado tiene tanto una obligación no solo reactiva ("combatir"), sino también proactiva ("reconocer"). Sobre el primer punto, la acción más clásica, pero interrelacionada estrechamente a las demás dimensiones, es la obligación del Estado de prohibir la discriminación. Así, el numeral 2 del artículo 5 al usar la fórmula de "toda discriminación”, permitió al Comité especificar que esta cláusula incluye la discriminación directa, indirecta, por "denegación de ajustes razonables", por acoso, múltiple, interseccional, por asociación y por motivos de discapacidad pasada, futura y presunta ${ }^{150}$. Pero no debe soslayarse que al estar interrelacionada con las otras dimensiones de la igualdad, este deber positivo de los Estados se posiciona más allá de una perspectiva individual; es decir, no solo busca neutralizar el acto discriminatorio individual, sino también enfrentar las causas estructurales que lo originan. Por este motivo, para combatir estos patrones enquistados en la estructura de la sociedad, debe identificarse quién está en una "mejor posición para tomar medidas para abordar las desigualdades"151 y articular, así, una respuesta institucional. De otro lado, el segundo punto de esta dimensión se refiere a las actividades vinculadas al ámbito cultural, que permitan reconocer las diferencias de las personas con discapacidad sin prejuicios y a "preservar su identidad"152, siendo estos deberes de sensibilización desarrollados principalmente en el artículo 8 de la CDPD-ONU sobre "toma de conciencia”. Estas, sin duda, están ligadas al combate contra toda discriminación, al ser actividades dirigidas a prevenir su realización.

Ahora bien, un punto clave que el Comité hizo explícito es la referencia

148 Comité sobre los Derechos de las Personas con Discapacidad (2018), p. 3.

149 FREDMAN (2011), pp. 28-30.

150 Comité sobre los Derechos de las Personas con Discapacidad (2018), pp. 5-6.

151 FREDMAN (2011), p. 302.

152 FREDMAN (2011), p. 99. 
al concepto de interseccionalidad, término no empleado por la CDPDONU al utilizar la expresión "múltiples formas de discriminación". Pese a esta omisión, de la lectura de la Convención, sobresale la presencia de las distintas identidades que pueden conjugarse con la experiencia de la discapacidad, al tratar, por ejemplo, la situación de discriminación agravada de quienes son también mujeres (artículo 6), niños y niñas (artículo 7) o personas privadas de libertad (artículo 14.2). Lo anterior también es notorio en el ámbito cultural de concientización, al establecer la obligación, por ejemplo, de eliminar los prejuicios o estereotipos que acumulan las personas con discapacidad en relación a su género y edad (literal b del artículo 8 de la CDPD-ONU). En todo caso, el enfoque de interseccionalidad supone que las reparaciones sean adecuadas en función al agravamiento de las desventajas, no debiendo ser limitadas a medidas específicas pensadas solo para situaciones de personas con discapacidad ${ }^{153}$.

Como vemos, la experiencia de discapacidad es potencialmente transversal a las distintas identidades que uno puede asumir en la vida en sociedad. Es por ello que es indispensable razonar la discapacidad de una forma interseccional, al cruzarse de manera indesligable con otras características que refuerzan la desventaja ${ }^{154}$. Por este motivo, Fredman y sus colegas critican la expresión "discriminación múltiple", al considerar que no refleja la dinámica que subyace al concepto de discriminación interseccional, ya que sugiere la posibilidad de dividir individualmente los motivos por los cuales uno es discriminado ${ }^{155}$. Lo cierto es que el Comité mantuvo esta distinción y, en todo caso, debe conciliarse este doble criterio en casos que involucren más de dos características protegidas a la luz de la experiencia de esta persona.

Pero la mención a la interseccionalidad no debe limitarse a una perspectiva antidiscriminatoria, tomando en cuenta el lado proactivo del reconocimiento, junto con sus interrelaciones con las otras dimensiones. Justamente, este deber de reconocimiento es lo que abre las posibilidades

153 FREDMAN et al. (2017), p. 14.

154 Arnardóttir (2009), pp. 62-63; Degener (2016), p. 17.

155 FREDMAN et al. (2017), pp. 12-13. 
para las personas neurodiversas de lograr reivindicaciones a través de la CDPD-ONU, a falta de un marco específico que reconozca su diversidad. $Y$ es que una persona neurodiversa puede potencialmente desarrollar alguna deficiencia como consecuencia de no haber recibido, por ejemplo, una atención en salud adecuada de manera preventiva. Del mismo modo, y aunque dé la impresión que se asimila su diversidad como deficiencia, no cabe duda que enfrentan tanto barreras sociales como actitudinales. Por ello, al reconocer que la identidad neurodiversa puede intersectarse con la de discapacidad, los Estados parte también tienen la obligación de promover positivamente la identidad de este grupo basado en una categoría diagnóstica (numeral 2 del artículo 8 de la CDPD-ONU).

\subsubsection{Dimensión participativa}

Esta dimensión, conforme señala el Comité, trata de reafirmar dos asuntos: "el carácter social de las personas como miembros de grupos sociales" y "el reconocimiento pleno de la humanidad mediante la inclusión en la sociedad"156. Fredman, de manera más escueta, señala que busca "facilitar la plena participación en la sociedad, tanto social como políticamente", lo que perfila que el campo de acción no se limita el ámbito público, sino también al privado ${ }^{157}$.

La participación es un eje necesario dentro de toda concepción sustantiva de igualdad, puesto que parte de considerar que la vida se realiza no de forma abstracta sino en un contexto social; es decir, que la experiencia humana incluye "la capacidad de participar en igualdad de condiciones en la comunidad"158. En el caso de las personas con discapacidad, los Estados parte asumen un deber de garantizar la accesibilidad a esta vida en sociedad, lo cual es plasmado en el artículo 27 (ámbito del empleo), el artículo 23 (ámbito familiar), el artículo 29 (ámbito político) o el artículo 30 (ámbito cultural) de la CDPD-ONU, por mencionar algunos ejemplos generales.

156 Comité sobre los Derechos de las Personas con Discapacidad (2018), p. 3.

157 FREDMAN (2011), p. 25.

158 FREDMAN (2011), p. 32. 
Al igual como ocurría en los anteriores casos, esta dimensión interactúa cercanamente con sus pares. Por ejemplo, podemos interrelacionarla con la dimensión redistributiva en las acciones afirmativas que pudieran realizarse en el ámbito del empleo en el sector privado (literal h del artículo 27 de la CDPD-ONU) o en el político, considerando la subrepresentación existente de personas con discapacidad mental159. Podemos pensar también en las acciones para combatir las barreras de acceso al ámbito político que resultan de los prejuicios hacia este grupo desaventajado, acciones que entrelazarán tanto esta dimensión como la de representación. Por último, un ejemplo que relaciona tanto la dimensión de participación con la de ajustes lo encontramos en situaciones en las que brindar acceso a un colegio será insuficiente si no se complementa con ajustes individualizados que garanticen la inclusión plena en el sistema educativo (artículo 24 de la CDPD-ONU).

\subsubsection{Dimensión transformadora o de ajustes}

La cuarta y última dimensión del modelo de igualdad inclusiva que la Comisión desarrolla tiene como finalidad "dar cabida a la diferencia como aspecto de la dignidad humana"160. De acuerdo a Fredman, esta dimensión busca "respetar y acomodar la diferencia, eliminando el detrimento, pero no la diferencia en sí misma", que permita a los grupos desaventajados no tener que ajustarse "a la norma dominante" $\mathrm{y}$, de este modo, llegar a "lograr un cambio estructural"161. Lo que encarna esta dimensión es, en última instancia, el principio de diferencia y el enfoque basado en grupos desaventajados que lleve a transformar el entorno en un espacio de realización de esta diferencia ${ }^{162}$.

159 HumAN Rights WATCH (2012), pp. 78-84. Esta organización reseñó además cómo la desigualdad en la capacidad jurídica que había en el Perú fomentó el prejuicio hacia las personas con discapacidad mental en el ámbito electoral. Es así que se desarrollaron políticas, desde el Registro Nacional de Identificación y Estado Civil (RENIEC) del Perú, que llegaron a excluir "a más de 20,000 personas con discapacidad intelectual o psicosocial del padrón electoral”. HumAN RIGHTS WATCH (2012), pp. 43-48.

160 Comité sobre los Derechos de las Personas con Discapacidad (2018), p. 3.

161 FREDMAN (2011), pp. 25, 30.

162 ARNARDÓtTIR (2009), pp. 64-65. 
Abordar este punto nos regresa a la discusión entre lo individual y lo estructural, pues refleja la tensión entre ajustar a la persona a la sociedad o que la sociedad se ajuste a ella. Esta dimensión lidia con esta dicotomía, al centrarse en la diferencia y las posibles acciones que permitan su inclusión en la vida social. Por ello, tales acciones resultan ser idiosincráticas, en el sentido que deben adecuarse a cada experiencia concreta de discapacidad mental de una persona. Deben poder distinguir, sobre todo, qué es o no es un detrimento en un caso específico, el cual puede ubicarse incluso en el propio individuo.

Por ejemplo, sería compatible con este modelo de igualdad brindar atención médica a una persona con discapacidad mental a fin de prevenir que desarrolle potenciales discapacidades físicas, siempre que tales acciones no encubran, en realidad, un ajuste que la sociedad impuso. Es así que, en este caso, los ajustes que reciba una persona con discapacidad mental deben ser consecuencia de sus necesidades concretas, por lo que resulta también necesario garantizar su participación en la toma de decisiones médicas.

Como puede apreciarse, bajo este modelo, lo individual adquiere una proyección distinta en su interrelación con las distintas dimensiones de la igualdad, si lo contrastamos con el significado que recibiría bajo una perspectiva individualista como la del modelo médico. Cuestión similar ocurre con lo estructural, pues esta dimensión muestra que las medidas adoptadas a nivel individual tienen la capacidad de transformar las propias estructuras que originan las desventajas de este grupo heterogéneo. Ambos aspectos, en suma, evidencian cómo lo estructural y lo individual están interrelacionados en la dimensión transformadora de este modelo de igualdad. Desde luego, esto no impide reconocer, al mismo tiempo, que la mayor parte de desventajas son externas al individuo, hecho que guarda relación con la proporción de deberes que los Estados parte tienen en materia social y cultural en la CDPD-ONU.

En un sentido más angosto, la CDPD-ONU ofrece el concepto de ajustes razonables como principal expresión de esta dimensión, el cual hace referencia a "las modificaciones y adaptaciones necesarias y adecuadas que no impongan una carga desproporcionada o indebida, cuando se 
requieran en un caso particular" (artículo 2). Conforme el Comité lo ha desarrollado, estos ajustes forman parte de la obligación "de no discriminar en el contexto de la discapacidad", en específico, por "denegación de ajustes razonables", obligación que es distinta en naturaleza que las de accesibilidad (artículo 9 de la CDPD-ONU), las cuales son obligaciones ex ante ${ }^{163}$. Por este motivo, los ajustes razonables son una "obligación reactiva individualizada" y, en consecuencia, una obligación ex nunc que solicita la persona con discapacidad ante un obstáculo que le impide el goce de alguno de sus derechos fundamentales ${ }^{164}$.

\subsection{La relación entre el modelo de igualdad inclusiva de la CDPD-ONU y el enfoque de igualdad real de oportunidades del Tribunal Constitucional peruano}

Habiendo presentado en qué consiste el modelo de igualdad inclusiva que trae la CDPD-ONU, resulta importante interrogarnos si este modelo compite con la noción de igualdad real de oportunidades del Tribunal Constitucional peruano ${ }^{165} \mathrm{o} \mathrm{si}$, en todo caso, lo complementa. Responder esta pregunta tiene dos niveles. El primero consiste en evaluar la compatibilidad entre las matrices teóricas detrás del modelo de igualdad inclusiva (Sandra Fredman) y el de igualdad real de oportunidades (Nancy Fraser). El segundo nivel de análisis está en lo delineado por el Tribunal Constitucional y su contraste con el modelo de igualdad de la CDPD-ONU.

Comenzando en el nivel teórico, Fraser plantea, más que una teoría sobre la igualdad, una teoría de la justicia multiescalar —bivalente en sus primeras formulaciones - que busca la paridad participativa en la sociedad $^{166}$. Para lograr esta paridad, se requiere tomar una serie de "arreglos sociales que permitan que todos los miembros (adultos) de la sociedad

163 Comité sobre los Derechos de las Personas con Discapacidad (2018), p. 7.

164 Comité sobre los Derechos de las Personas con Discapacidad (2018), p. 7.

165 Sentencia del Tribunal Constitucional N 01272-2017-PA, de 5 de marzo de 2019, fundamento jurídico 13.

166 Fraser (2010); Fraser (1996), pp. 32-36. 
interaccionen entre ellos como iguales"167, en tres escalas interrelacionadas: socioeconómica ("distribución de los recursos materiales"), cultural ("modelos culturales de interpretación y valoración sean de tal manera que permitan expresar un respeto mutuo para todos los participantes y asegurar la igualdad de oportunidades para conseguir estimación social") y política ("voz política más o menos igual a todos los actores sociales") ${ }^{168}$. En ese orden, los remedios ante las injusticias serán la redistribución, el reconocimiento y la participación política ${ }^{169}$.

Si bien Fredman se nutre de los desarrollos teóricos de Fraser $^{170}$, lo que presenta es propiamente una teoría de la igualdad. En vez de incardinar la igualdad bajo conceptos como el de paridad, igualdad de oportunidades o igualdad de trato, ella la ubica dentro de la tradición de teorías asimétricas que tienen en su centro de preocupación la desventaja de los distintos grupos sociales, pero con el distintivo de reconocerle su multidimensionalidad. Esto es lo que articula el modelo tetradimensional de Fredman.

En cuanto a otras diferencias entre ambos planteamientos, interesa en especial destacar cuatro. De un lado, la más evidente es la ausencia de una escala individualizada que refleje la dimensión transformadora de Fredman, consecuencia tal vez de que esta dimensión represente el enfoque basado en la corrección particular de desventajas grupales que, como vimos, no es el eje central de la teoría multiescalar de Fraser. De otro lado, la dimensión de redistribución va más allá de la mera preocupación escalar por la adecuada distribución de bienes, si consideramos que Fredman encuadra aquella dimensión en el objetivo de combatir el ciclo de desventajas que afecta a los grupos externos. Como tercera diferencia tenemos que Fredman incorpora el elemento de participación como una dimensión, pero en un entendimiento más amplio respecto de la escala política. Este entendimiento amplio de la participación no

167 FRASER (1996), p. 32.

168 El entrelazamiento de las escalas es reflejo, según esta autora, de las intersecciones existentes entre las categorías de los sujetos y las injusticias. FRASER (2010), p. 365.

169 FRASER (2010), p. 366.

170 FREDMAN (2011), pp. 35-36. 
es que esté ausente en el enfoque de Fraser, sino que resulta ser el eje articulador de las demás escalas, lo que nos lleva a la última diferencia. Mientras Fraser articula sus tres escalas bajo la noción de la paridad participativa, Fredman no establece una subordinación entre las dimensiones, siendo las cuatro reflejo del carácter multidimensional de las desventajas grupales.

Pese a la diferencias, el modelo mutidimensional de Fredman puede ser leído también como un desarrollo de la teoría de la justicia de Fraser, adaptado a una teoría jurídica de la igualdad que pone en el centro de sus preocupaciones a las desventajas que experimentan los distintos grupos en sociedad. Es por ello que ambos planteamientos no son en sí incompatibles, al margen de estimar que uno sea más integral que el otro.

Ahora bien, al contrastar lo delineado por el Tribunal Constitucional peruano con el modelo de igualdad inclusiva de la CDPD-ONU, debemos comenzar observando que el Tribunal incorporó la teoría de Fraser al tratar en un caso el derecho de igualdad desde una perspectiva estructural, pero de forma parcial al solo reconocer la escala de redistribución -la cual solo menciona sin mayor desarrollo- y la de reconocimiento ${ }^{171}$. La omisión a la escala de participación política puede explicarse en la cita que el Tribunal realizó a un artículo de Fraser en el que su teoría de la justicia era aún bivalente y no multiescalar.

Como segunda cuestión vemos que las escalas de reconocimiento y redistribución son subordinadas por el Tribunal al concepto de igualdad real de oportunidades. Tal como hicimos referencia al inicio del artículo, la acepción sustantiva de este concepto viene siendo desarrollada por la academia argentina ${ }^{172}$ sobre la base de una perspectiva estructural y asimétrica, de modo tal que refleje el concepto de paridad participativa de Fraser. Lo cierto es que esta decisión terminológica puede criticarse tanto por unidimensionar la igualdad bajo este concepto, como por asumir la

171 Sentencia del Tribunal Constitucional N 01272-2017-PA, de 5 de marzo de 2019, fundamentos jurídicos 14-15

172 Grosman (2008); Saba (2012); Ronconi (2019); Clérico y Aldao (2011). 
carga ideológica que supone el término "oportunidad", muy cercana a la noción de mérito ${ }^{173}$. En el caso argentino, comprendemos que esta inclinación hacia el concepto de igualdad real de oportunidades resulta de su mención en el numeral 23 de su artículo 75 de su Constitución. Situación distinta ocurre en el Perú, pues no cuenta con tal definición en su Carta Fundamental, por lo que el Tribunal Constitucional pudo considerar otra expresión.

De otro lado, los remedios bajo el enfoque de igualdad del Tribunal parten de una posición intermedia, ya que establecen tanto acciones reparadoras como transformadoras a fin de corregir las desigualdades estructurales $^{174}$. En el modelo de igualdad inclusiva, en cambio, ambas medidas específicas son integradas no como consecuencia de buscar una posición ecléctica, sino por la naturaleza multidimensional de las desventajas que requieren corregirse.

Finalmente, las líneas anteriores nos permiten concluir que el modelo asumido por el Tribunal Constitucional en sí no compite con el modelo de igualdad inclusiva de la CDPD-ONU, pero es incompleto a la luz de éste. No siendo incompatibles teóricamente, es necesario que el Tribunal trabaje en la incorporación de las medidas de ajuste y de participación, en sentido amplio, ausentes en su nueva concepción de igualdad como no sometimiento. Más allá de estos desajustes, cabe reconocer el avance que supone iniciar esta línea de análisis estructural del derecho de igualdad, que puede ser valiosamente complementado por el modelo de igualdad inclusiva de la CDPD-ONU.

\section{Los desarrollos del Tribunal Constitucional peruano en la protección de las personas con discapacidad mental: del derecho a la salud a los derechos de la discapacidad}

Las personas con discapacidad mental, como anunciábamos, traen en sí un reto para la reflexión constitucional, que es remediar la expe-

173 díaz de Valdés (2015), pp. 176-177; Fredman (2011), p. 18.

174 Sentencia del Tribunal Constitucional N ${ }^{\circ}$ 01272-2017-PA, de 5 de marzo de 2019, fundamento jurídico 13. Sobre en qué consisten estos remedios, véase Ronconi (2019), p. 135. 
riencia de su desventaja. Para ello, nos hemos valido de reconocer esta realidad a través de la discusión sobre su concepto, como también desde el marco evaluativo sobre las demandas de igualdad a favor de este colectivo que provee la CDPD-ONU. A su vez, ambas cuestiones llevan consigo disrupciones al tratamiento que ha venido teniendo las personas con discapacidad mental en materia de igualdad. Por ello, estudiaremos ahora las sentencias más relevantes del Tribunal Constitucional peruano sobre este grupo desaventajado, para no solo revisar su trayecto, sino también advertir críticamente las omisiones que no consideró al momento de evaluar las demandas, a la luz de lo desarrollado en las anteriores dos secciones.

Este ejercicio nos permitió identificar que el Tribunal ha emitido pocas sentencias en materia de personas con discapacidad mental y, de ellas, ninguna tiene como punto central el principio-derecho de igualdad. Salvo una sentencia del año 2019175, la mayoría son analizadas desde el derecho a la salud, en respuesta a la ligazón que la Constitución peruana plantea entre salud y discapacidad ${ }^{176}$. Pese a esta carencia, dar lectura a estas sentencias desde el marco multidimensional de la igualdad permite trazar los retos que debe asumir el Tribunal Constitucional para garantizar los derechos fundamentales de este grupo desaventajado, más aun considerando la vigencia de la CDPD-ONU en el Perú. Así, trabajaremos sobre la base de seis sentencias, que hemos identificado como las más relevantes sobre las personas con discapacidad mental, pero centrándonos en ciertos aspectos que permitan articularlo con el modelo de igualdad inclusiva.

175 Sentencia del Tribunal Constitucional Nº0194-2014-PHC, de 30 de abril de 2019.

176 El artículo 7 aborda tanto el derecho a la salud como la "protección al discapacitado", en estos términos: "Todos tienen derecho a la protección de su salud, la del medio familiar y la de la comunidad así como el deber de contribuir a su promoción y defensa. La persona incapacitada para velar por sí misma a causa de una deficiencia física o mental tiene derecho al respeto de su dignidad y a un régimen legal de protección, atención, readaptación y seguridad”. 


\subsection{R.J.S.A. viuda de R., a nombre propio y en su calidad de curadora representante de su hija G. R. S. c. sentencia de la Quinta Sala Civil de la Corte Superior de Justicia de Lima (Exp. 3081-2007-PA, 9/11/2007)}

Este caso giró en torno a un informe médico que daba de alta de un centro hospitalario a una persona con esquizofrenia, pues, habiendo transcurrido el tiempo de internamiento, se requería continuar el tratamiento médico desde el espacio familiar. El problema surge al implicar esta decisión que las responsabilidades recayesen en la madre, quien era una anciana viuda sin posibilidades para hacerse cargo de los costos del referido tratamiento. Por este motivo, la madre demandaba que el hospital asumiera el internamiento permanente de su hija, en salvaguarda de su salud, pretensión amparada por este alto Tribunal, al ordenar la "atención médica y hospitalización permanente e indefinida" de esta persona.

Por los términos de dicha pretensión, este caso fue abordado desde el derecho fundamental a la salud mental, dando apertura a que su análisis implique no solo un conocimiento jurídico, sino médico y de ciencias sociales ${ }^{177}$. Delinea, además, como "población altamente vulnerable" a las personas que presenten enfermedades mentales, siendo estas un "problema de salud pública" que requiere del Estado el desarrollo de un "conjunto de acciones positivas a fin de que el derecho a la salud no sea un ideal"178. Así, bajo esta perspectiva patológica que asume el Tribunal, denominada dignificadora, las personas con discapacidad mental eran "enfermos mentales", quienes podrían ser integrados socialmente en la medida que fueran curados, estando proscrito el "método intramural"179.

Esta perspectiva era marcadamente preventiva, incluso promoviendo que se emitiera políticas para identificar "enfermedades mentales a

177 Sentencia del Tribunal Constitucional $N^{\circ}$ 3081-2007-PA, de 9 de noviembre de 2007, fundamento jurídico 25.

178 Sentencia del Tribunal Constitucional $N^{\circ}$ 3081-2007-PA, de 9 de noviembre de 2007, fundamentos jurídicos 25-26.

179 Sentencia del Tribunal Constitucional N³081-2007-PA, de 9 de noviembre de 2007, fundamento jurídico 41. 
fin de prevenirlas y detectarlas para recibir un tratamiento oportuno"180. En el fundamento jurídico 44, el Tribunal atribuye al desconocimiento de la población sobre las enfermedades mentales fungir como una barrera para el tratamiento preventivo de estas, aunque reconoce el rol de los prejuicios. También está implícita la idea de que las enfermedades mentales son causadas socialmente por factores como la violencia política, la violencia juvenil o la falta de oportunidades ${ }^{181}$.

Entre otras cuestiones, el Tribunal resalta en el fundamento jurídico 34 que el Derecho Internacional de los Derechos Humanos en materia de salud mental busca, en última instancia, el "logro de la rehabilitación y a un tratamiento que estimule la independencia personal, la autosuficiencia y la integración social del discapacitado con proscripción del método intramural y a ser tratado en igualdad de condiciones, sin discriminación y en estricto respeto de sus derechos fundamentales".

Respecto a esta sentencia, al construirse el razonamiento solo desde el derecho a la salud mental, el Tribunal unidimensionó el problema que enfrentaba, el cual no implicaba solo la desventaja socioeconómica que afrontan las personas con discapacidad mental. La reparación individual en este caso se limitó a mantener la distribución de la responsabilidad de la desventaja en la esfera pública, pero sin considerar la dimensión de participación de la igualdad, que hubiera llevado a considerar otorgar apoyo social y tratamiento ambulatorio a la persona, a fin de que pueda realizarse su inclusión en la sociedad. Vale la pena resaltar que fueron los propios médicos que tuvieron consideración de este aspecto social en su informe de alta, en contraste al Tribunal, que planteó un modelo de inclusión basado en la rehabilitación individual.

Ahora bien, verlo solo como un problema de salud es el resultado de estar ante una sentencia que construye el concepto de discapacidad mental como enfermedad, por lo que resulta coherente que la solución

180 Sentencia del Tribunal Constitucional N³081-2007-PA, de 9 de noviembre de 2007, fundamento jurídico 40.

181 Sentencia del Tribunal Constitucional N³081-2007-PA, de 9 de noviembre de 2007, fundamentos jurídicos 43,48 . 
solo respondiera a este encuadramiento individual. Es cierto que el Tribunal deja entrever que las enfermedades mentales tienen una causa social, lo cual es cuestionable si consideramos su etiología multifactorial. Pero, al estar bajo esta perspectiva médico-individual, queda al final como un comentario sin una respuesta jurídica y lejos de dirigirse hacia un desarrollo enfocado en reparar desventajas más allá de la cuestión sanitaria y del propio caso concreto.

\subsection{Matilde Villafuerte viuda de Medina, en su calidad de curadora de Ramón Medina Villafuerte c. sentencia de la Segunda Sala Civil de la Corte Superior de Justicia de Lima (Exp. 02480-2008-PA, 11/07/2008)}

De manera similar al anterior caso, por medio de este proceso de amparo, se solicita dejar sin efecto un informe médico que da de alta a un interno psiquiátrico que estuvo doce años en tal situación, por vulnerar el derecho fundamental a la salud. Si bien el hospital aduce que logró aliviar su "sintomatología psicótica" y que recibirá atención ambulatoria, la madre, quien asumiría la responsabilidad de su cuidado, señala que por su condición es peligroso y que ella misma padece de una enfermedad mental. Cabe resaltar la afirmación de EsSalud, quien señala que "el estado de salud del favorecido nunca va a ser normal, pero que ello no implica que tenga que permanecer internado toda su vida", siendo necesario para su mejoramiento "la interrelación familiar" que puede recibir en su hogar.

En esta sentencia es que el Tribunal establece que las personas con discapacidad mental son "sujetos de especial protección" a fin de que puedan ejercer, a falta de "autodeterminación", sus derechos, lo que significa que el Estado adopte, en garantía del derecho a la salud mental, "medidas positivas adecuadas para reducir las desventajas estructurales" y tratos preferentes para lograr "su plena participación y readaptación e igualdad dentro de la sociedad para todas ellas"182. La responsabilidad de

182 Sentencia del Tribunal Constitucional $N^{\circ}$ 02480-2008-PA, de 11 de julio de 2008, fundamento jurídico 13. 
brindar esta "protección reforzada" recaería en las entidades que presten servicios de salud, lo cual puede extenderse incluso a las entidades privadas, conforme a lo que señala en el fundamento jurídico 17 . De otro lado, destaca cómo el Tribunal conceptualiza el derecho a la salud como "la facultad inherente a todo ser humano de conservar un estado de normalidad orgánica funcional" y "prevenirlo y restituirlo ante una situación de perturbación del mismo"183.

En el fundamento jurídico 19, el Tribunal Constitucional invoca el principio de solidaridad para argumentar que, dada las carencias del espacio familiar, el Estado debe asumir la protección de las personas con discapacidad mental, que en este caso significa la "atención médica y hospitalización permanente e indefinida”. Por esta situación familiar particular, declara fundada la demanda, a pesar de ser contraria al "derecho a no permanecer internadas de manera definitiva" que reconoce el Derecho Internacional de Derechos Humanos ${ }^{184}$. Finaliza con una serie de exhortaciones para que el Estado brinde atención psiquiátrica a nivel nacional.

Nuevamente aquí estamos ante una falta de equilibrio entre la dimensión redistributiva y la participativa, como consecuencia de tratar este caso principalmente como un problema médico. Pero dentro de las consideraciones que realiza el Tribunal, es necesario puntualizar lo siguiente. En primer lugar, la manera en cómo define el derecho a la salud se inspira en una concepción dicotomizada de lo que implica el bienestar individual. Esto resulta, seguramente sin intención, en el reforzamiento de los prejuicios sobre la categoría de enfermedad y, en consecuencia, de discapacidad mental. Lo segundo es que esta sentencia reconoce explícitamente que las desventajas estructurales son el problema de las personas con discapacidad mental, mencionando ligeramente las dimensiones redistributiva, transformadora y de participación. Pese a esta referencia, al seguir estando en un encuadramiento individual, este recono-

183 Sentencia del Tribunal Constitucional N 02480-2008-PA, de 11 de julio de 2008, fundamento jurídico 6.

184 Sentencia del Tribunal Constitucional N 02480-2008-PA, de 11 de julio de 2008, fundamento jurídico 26 . 
cimiento no se expresó ni en la reparación ni en ir más allá del derecho a la salud mental.

\subsection{Miguel Ángel Morales Denegri a favor de los internados en la sala de hospitalización de adicciones del Instituto Nacional de Salud Mental Honorio Delgado-Hideyo Noguchi c. sentencia de la Segunda Sala Penal de Procesos con Reos Libres de la Corte Superior de Justicia de Lima (Exp. 05842- 2006-PHC, 7/11/2008)}

La demanda de habeas corpus presentada contra un Instituto de Salud Mental del Ministerio de Salud peruano tuvo como motivo el tratamiento intramural sin consentimiento informado previo ("internamiento impropio") de una serie de pacientes psiquiátricos que, además, no estaban diferenciados ("condiciones inadecuadas") con quienes estaban ahí por adicciones y que eran caracterizados como violentos ${ }^{185}$. Planteado al inicio como un caso sobre el derecho a la libertad personal, el Tribunal lo abordó principalmente como una violación al derecho a la salud mental por conexidad. Ahora, entre las distintas cuestiones que desarrolla, destacamos lo siguiente.

El Tribunal realiza una labor de distinción sobre "los problemas mentales de salud", que estarían compuestos por las personas con discapacidad mental y quienes tienen perturbaciones mentales (sujetos con adicciones $u$ otros trastornos psiquiátricos, por ejemplo), para luego interpretar que el artículo 7 de la Constitución incluye a estos últimos ${ }^{186}$. Asimismo, reitera en el fundamento jurídico 66 que las personas con discapacidad mental se encuentran en una "situación especial que no puede ser agravada por el entorno económico y social", por lo que requieren de "atención médica", "tratamiento físico" y asistencia familiar y económica. Agrega luego en el fundamento jurídico 69 que "están sujetas a prejuicios y fuertes estigmas, constituyendo un grupo vulnerable a violaciones de

185 Sentencia del Tribunal Constitucional N 05842-2006-PHC, de 7 de noviembre de 2008 , fundamento jurídico 40.

186 Sentencia del Tribunal Constitucional $N^{\circ}$ 05842-2006-PHC, de 7 de noviembre de 2008, fundamentos jurídicos 65,68 . 
derechos humanos a nivel global". Justamente, aquí identificamos un primer desarrollo de la dimensión de reconocimiento que debe ser transversal al análisis de la situación de las personas con discapacidad mental.

Pese a esto, el Tribunal reproduce un estigma sobre este grupo social, al afirmar que "dichas personas se encuentran en un nivel de inferioridad y dependencia que no se presenta necesariamente en el caso de las personas que padecen enfermedades físicas", que "incide en el normal desenvolvimiento de su personalidad en la sociedad"187. En todo caso, el Tribunal señala en el fundamento jurídico 125 que las personas con discapacidad mental requieren que los tratamientos médicos tengan como objetivo la rehabilitación, lo que permitirá "su reinserción en el seno familiar y social".

Surge aquí el problema de esencializar a este grupo social desaventajado a partir de ciertas características que no son el resultado de un trabajo serio de diferenciación. Las personas neurodiversas, por ejemplo, nos muestran que en muchos casos estamos ante expresiones cognitivas válidas y que no representan una situación de inferioridad. Lo cierto es que este aspecto de la sentencia grafica por qué la dimensión de reconocimiento de la igualdad no es compatible teóricamente con un modelo rehabilitador, incluso si reconoce las barreras actitudinales, como lo hizo el Tribunal. En suma, una visión unidimensional de la discapacidad mental, que limita las acciones redistributivas a la sanidad, impactará negativamente en la dimensión de reconocimiento de la igualdad sustantiva.

De otro lado, el Tribunal en el fundamento jurídico 47 se encargó de desarrollar el derecho-principio a la salud como "la potestad de exigir la no-afectación de su salud, y al mismo tiempo la obligación de coadyuvar en la promoción de dicho derecho". Para esto, plantea en el fundamento jurídico 44 que gozar de un "estado psicosomático pleno" permite "alcanzar el bienestar individual y colectivo". Se requiere, así, "medidas positivas de salud", que se traducen en prestaciones que permitan la "con-

187 Sentencia del Tribunal Constitucional $N^{\circ}$ 05842-2006-PHC, de 7 de noviembre de 2008, fundamentos jurídicos 61-70. 
servación y de restablecimiento del derecho a la salud"188. Enmarcadas dentro de las políticas sociales a favor de este grupo, estas permitirán "lograr progresivamente la plena efectividad de los derechos en igualdad de condiciones para la población en su conjunto"189. Vemos que de manera explícita se reconoce que lograr la simetría entre los sujetos de derecho implicará, para esta población desaventajada, acciones positivas conducentes a rehabilitarlos. Lamentablemente, tal objetivo es un resultado redistributivo coherente con la visión unidimensional sobre la causa de la desventaja de este grupo social de la que parte limitadamente el Tribunal.

\subsection{Luz Margarita Bustamante Candiotti c. sentencia expedida por la Segunda Sala Penal de la Corte Superior de Justicia de Lima (Exp. 2313-2009-HC, 24/09/2009)}

Este caso trata principalmente sobre el derecho a la libertad individual de una persona con discapacidad mental que se encuentra internada sin su deseo en un centro privado de atención y que generó la controversia entre sus familiares, que incluía a su curadora. El Tribunal declara fundada la demanda, pero señala que debe formarse un consejo de familia, el cual tiene como objetivo "velar por los intereses de los menores y de los incapaces mayores de edad"190. Aquí vemos que estos análisis concebían implícitamente la situación de este grupo desaventajado como análoga al de los menores de edad, lo que implica reproducir el prejuicio sobre su incapacidad de realización autónoma. Como vimos en anteriores secciones, la integración de este grupo a la sociedad implica reconocer una autonomía diseñada en los términos de esta diferencia.

A pesar de esta cuestionable analogía y en abierta contradicción, el Tribunal reconoce expresamente que "[l]a discapacidad mental no es si-

188 Sentencia del Tribunal Constitucional $N^{\circ}$ 05842-2006-PHC, de 7 de noviembre de 2008, fundamentos jurídicos 58-59.

189 Sentencia del Tribunal Constitucional N 05842-2006-PHC, de 7 de noviembre de 2008, fundamento jurídico 85.

190 Sentencia del Tribunal Constitucional N²313-2009-HC, de 24 de septiembre de 2009, fundamento jurídico 17. 
nónimo, prima facie, de incapacidad para tomar decisiones"191. Esta afirmación la realiza en el marco del respeto de la dignidad de las personas con discapacidad mental, lo que, desde el punto de vista de la multidimensionalidad de la igualdad, nos sitúa en la discusión sobre la dimensión de reconocimiento. Lamentablemente, el marco cultural bajo el que se dictó esta sentencia limitó las posibilidades de desarrollo de esta afirmación y su expresión en la reparación de este caso.

\subsection{Pedro Gonzalo Marroquín Soto c. sentencia de la Primera Sala Penal de Reos en Cárcel de la Corte Superior de Justicia de Lima Norte (Exp. 03426-2008-PHC, 26/08/2010)}

El Tribunal marcó una diferencia sustantiva en la resolución del presente caso, al invocar la figura del estado de cosas inconstitucional para remediar la situación de un grupo de personas privadas de libertad que no eran trasladados a hospitales para recibir tratamiento psiquiátrico, por cuestiones logísticas, negativa que vulneraba el derecho a la integridad personal. Si bien se planteó como un caso individual, a través de esta figura el Tribunal buscó extender los efectos de su resolución, al haber constatado, por medio de un informe de la Defensoría del Pueblo del Perú, que esta situación era sistemática ${ }^{192}$. Pese a que supone un avance, el empleo de esta figura ha sido criticado por sus limitados alcances en el desmantelamiento de las desigualdades estructurales, si lo comparamos con el caso colombiano ${ }^{193}$.

Tal como desarrolla este alto Tribunal, el internamiento médico tiene una connotación rehabilitante, ya que parte de considerar que "la mayoría de los desórdenes mentales pueden controlarse, tratarse y en muchos casos prevenirse"194. Por ello, que este grupo desaventajado siga en un

191 Sentencia del Tribunal Constitucional N²313-2009-HC, de 24 de septiembre de 2009, fundamento jurídico 6 .

192 Sentencia del Tribunal Constitucional N 03426-2008-PHC, de 26 de agosto de 2010, fundamento jurídico 5 .

193 RAMirez (2013).

194 Sentencia del Tribunal Constitucional N 03426-2008-PHC, de 26 de agosto de 2010, fundamentos jurídicos 13, 16. 
centro penitenciario sin "condiciones para el tratamiento médico" supone una vulneración a su derecho de salud mental e integridad personal ${ }^{195}$.

Es, entonces, un deber del Estado asumir una política de tratamiento, ya que las personas con enfermedades mentales "se encuentran en un estado de especial vulnerabilidad"196. Este deber se extendió ya no solo a los centros de prestación de salud, sino también al Ministerio de Economía, por ser quien asigna los presupuestos, exigiendo el Tribunal que laboren de manera coordinada para superar esta falencia "de naturaleza estructural"197. Pese a esta declaración, si analizamos el remedio otorgado, caeremos en la cuenta que se limitó a una acción reparadora, enfocada en obtener un resultado específico, pero sin lograr incidir en las causas estructurales que el mismo Tribunal reconoce. Es por ello que la dimensión redistributiva implica también acciones transformadoras, que garanticen una serie de derechos, no limitados al de salud, a la vez que vela por los impactos en las otras dimensiones de la igualdad.

Finalmente, cabe anotar que en el año 2019 hubo otra demanda de habeas corpus correctivo resuelto por el Tribunal, en el que tuvo ocasión de reiterar el estado de cosas inconstitucional "respecto de la falta de diagnóstico y tratamiento de la salud mental de las personas que se encuentran internadas en los establecimientos penitenciarios del país"198, sin añadir mayor análisis sobre las personas con discapacidad mental.

\subsection{José Antonio Guillén Tejada c. resolución de la Primera Sala Penal de Apelaciones de la Corte Superior de Justicia de Arequipa (Exp. 00194-2014-PHC, 30/04/2019)}

A través de este proceso de habeas corpus, el Tribunal Constitucional peruano tuvo la oportunidad de desarrollar el modelo de discapacidad

195 Sentencia del Tribunal Constitucional Nº3426-2008-PHC, de 26 de agosto de 2010, fundamento jurídico 35.

196 Sentencia del Tribunal Constitucional N 03426-2008-PHC, de 26 de agosto de 2010, fundamento jurídico 19.

197 Sentencia del Tribunal Constitucional N 03426-2008-PHC, de 26 de agosto de 2010, fundamentos jurídicos 27, 31.

198 Sentencia del Tribunal Constitucional № 04007-2015-PHC, de 27 de junio de 2019, fundamento jurídico 81. 
que plantea la CDPD-ONU, respecto al caso de una persona con discapacidad mental que se encontraba viviendo en un ambiente familiar enrejado y con ventanas tapiadas. El padre de esta persona demandaba que estas medidas tomadas por su madre vulneraban sus derechos al libre tránsito y a la integridad personal, mientras que ella adujo que tomó tales medidas en salvaguarda de su hijo, quien podía además ser un peligro, tanto para ella como para terceros.

El Tribunal desarrolla una serie de consideraciones sobre el modelo social que estaría tras la CDPD-ONU, afirmando que la discapacidad es externa a la persona, ubicada en las "estructuras y comportamientos de la sociedad" y que, por tanto, dificultades visuales u otras deficiencias "es una condición de la diversidad humana"199. De manera poco clara, plantea en el fundamento jurídico 46 que "el concepto de discapacidad mental es más amplio que el de personas con problemas de salud mental", ya que sin barreras sociales las personas con tales problemas no tendrían discapacidad mental. Más allá de esto, se busca que "la sociedad se adapte a las necesidades de estas personas, en vez que ellas lo hagan por medio de curas, como se pretendía en el modelo médico ${ }^{200}$. En suma, el Tribunal parte del concepto de discapacidad como constructo social, noción que le permitiría combatir "las desigualdades que históricamente han aquejado a este importante sector de la población"201.

Lo que vemos tras este razonamiento es la adopción teórica del modelo social rígido a partir de una lectura posible de la CDPD-ONU, pero no única, como planteamos. Eso lleva a lidiar con el problema conceptual sobre los tratamientos de salud de la discapacidad mental, sean individualizados o preventivos, de una manera contradictoria, pues si la deficiencia es parte de la diversidad humana, buscar eliminarla iría en contra de este bien constitucionalmente protegido. Una lectura que armonice

199 Sentencia del Tribunal Constitucional N 00194-2014-PHC, de 30 de abril de 2019, fundamento jurídico 12.

200 Sentencia del Tribunal Constitucional N00194-2014-PHC, de 30 de abril de 2019, fundamento jurídico 13.

201 Sentencia del Tribunal Constitucional N00194-2014-PHC, de 30 de abril de 2019, fundamento jurídico 18. 
con la experiencia de las personas con discapacidad mental, en todo caso, hubiera partido de una matriz interaccional, que permita incluir la cuestión de salud como un campo de acción factible, pero sin afectar la dimensión de reconocimiento de la igualdad. De otro lado, contribuye a esta confusión el hecho de afirmar que el concepto de discapacidad mental es un universo más amplio que el de las categorías diagnósticas, bajo la sugerencia que la discapacidad mental es sinónimo de las barreras sociales. Como hemos analizado, la experiencia de la discapacidad mental parte de la realidad de la deficiencia, que puede constituir potencialmente una desventaja incluso sin la existencia de barreras sociales y culturales. No obstante esta equivocación, es cierto lo que menciona el Tribunal, respecto a que el concepto de discapacidad mental jurídicamente puede ser más amplio, considerando que es capaz de comprender a quienes han tenido o están predispuestos a desarrollar una discapacidad mental futura, así como las personas asociadas a este grupo social202.

Más allá de lo anterior, el Tribunal reitera en el fundamento jurídico 35 la consideración de las personas con discapacidad mental como "sujetos de especial protección constitucional" y rechaza, a la vez, que sean tratadas como meros objetos del proceso, concepción que debiera superarse a fin de empezar a comprenderles como verdaderos sujetos en el mismo. Solo así podrá garantizarse fehacientemente "el respeto de su derecho a la capacidad jurídica en condiciones de igualdad"203.

En este contexto, el Tribunal confirma la posibilidad excepcional de un tratamiento intramural permanente, señalando ahora que no hay consenso en el Derecho Internacional de los Derechos Humanos sobre los alcances del derecho a la libertad personal de las personas con discapacidad y que en los casos pasados "la precaria realidad del sistema de salud mental" y las circunstancias familiares lo justificaron ${ }^{204}$. Así, en el fundamento jurídico 60 declara la progresividad de la "desaparición ab-

202 Comité sobre los Derechos de las Personas con Discapacidad (2018), p. 19.

203 Sentencia del Tribunal Constitucional N 00194-2014-PHC, de 30 de abril de 2019, fundamento jurídico 33.

204 Sentencia del Tribunal Constitucional N00194-2014-PHC, de 30 de abril de 2019, fundamentos jurídicos $58,52$. 
soluta" del tratamiento intramural y que el Estado debe implementar "un modelo de atención comunitario".

Por último, establece que es a la familia "a quien le corresponde, en primer lugar, velar por la salud y el bienestar emocional de las personas con discapacidad de su entorno", aunque atenúa esta afirmación, reiterando el rol tuitivo del Estado respecto a esta población y la necesidad de desarrollar políticas públicas en salud mental ${ }^{205}$.

Como hemos apreciado, el Tribunal Constitucional desaprovecha esta sentencia para enfocar el problema principalmente desde el principio-derecho de igualdad, más aún que la CDPD-ONU parte de reconocerlo como una cuestión transversal. Aun si no partía del enfoque multidimensional que asume el Convenio, el Tribunal pudo desarrollar en el presente caso su noción de igualdad real de oportunidades para velar por la inclusión de esta persona a la sociedad, que no pasaba por una reparación limitada a un resultado concreto como la que fue otorgada. En suma, hizo falta un análisis estructural de la situación de desventaja de las personas con discapacidad mental y su contrapartida en una reparación transformadora.

\section{A modo de conclusión: los retos constitucionales pendientes en la protección inclusiva de las personas con discapacidad mental}

A lo largo de este artículo, hemos procurado mantener un enfoque asimétrico de igualdad que considere seriamente las diferencias que estructuran la experiencia de discapacidad mental. Ello supuso revisar la dicotomía entre definiciones patológicas y construccionistas puras sobre la discapacidad, para dar cuenta de que estas visiones extremas no representan con exactitud la experiencia de la discapacidad. $Y$ es que ambas definiciones llevan a dividir la apreciación sobre las desventajas experimentadas por las personas con discapacidad mental, al plantearlas o como una cuestión interna al individuo o como un problema exclusivamente externo a él, lo que condiciona cualquier posterior tratamiento.

205 Sentencia del Tribunal Constitucional Nº0194-2014-PHC, de 30 de abril de 2019, fundamentos jurídicos 69, 37. 
Así, mientras un modelo médico rígido demandará acciones clínicas individuales, su contraparte social requerirá modificar las estructuras socioculturales a través del derecho para superar tal experiencia. Sin embargo, la superación de las desventajas de este grupo implica esfuerzos conjuntos e interrelacionados tanto a nivel individual como estructural, tal como hemos desarrollado a lo largo del trabajo.

Esta discusión nos condujo, después, a examinar la CDPD-ONU, que constituye el marco global que particulariza los derechos humanos al caso de las personas con discapacidad. Apreciamos cómo su MDDH no es exactamente un modelo social rígido, ya sea por considerar a las deficiencias como parte de su definición de discapacidad, o por establecer deberes que responden a las desventajas originadas por condiciones individuales. De este modo, y a la luz de lo regulado en la propia CDPDONU, el MDDH como mínimo no es un modelo social ortodoxo, conclusión que contrasta con la justificación recurrente de este modelo en el construccionismo social. Así, sostenemos que, por ejemplo, una concepción más pragmática para abordar este marco jurídico global hubiera sido la del realismo crítico, que atiende a los cuestionamientos formulados tanto al modelo social como al médico, y propone, como alternativa, una definición de discapacidad formada por la interacción entre las deficiencias individuales y las barreras externas. Esta definición, por lo demás, es compatible con la CDPD-ONU.

Ahora bien, una de las premisas de este trabajo es que toda perspectiva orientada a los grupos desaventajados debe realizar una labor seria de diferenciación, si pretende evitar caer en esencialismos. Esto nos permitió identificar la existencia de un fuerte movimiento disruptivo al concepto de discapacidad mental. La neurodiversidad es precisamente un grupo social emergente que cuestiona su asimilación dentro de la categoría de personas con discapacidad mental, al estar su experiencia basada en la idea de diversidad cognitiva. Reconocer a este grupo, además, nos hizo cuestionar si sus demandas por una neuroigualdad que les permita una vida independiente podían ser canalizadas por la CDPD-ONU, ante la falta de un marco particular que reconozca su estatus diferenciado. Concluimos que es posible, considerando que es un objetivo que busca 
la propia CDPD-ONU, además de la posibilidad de que las identidades neurodiversas y de discapacidad se intersecten.

Luego de haber expuesto este planteamiento conceptual, el trabajo pasó a analizar dos esquemas basados en el derecho de igualdad, que están dirigidos a afrontar la desventaja que experimentan las personas con discapacidad mental. El primero proviene del MDDH de la CDPDONU, el cual es un modelo de igualdad inclusiva que busca garantizar la realización y el respeto de las personas con discapacidad en la sociedad. Al rastrear la matriz teórica de este modelo, identificamos que las ideas de Sandra Fredman inspiraron su diseño, al fundamentarse en su propuesta de igualdad transformativa. Vimos que, más allá del cambio de nomenclatura, materialmente eran lo mismo, al configurarse el modelo en cuatro dimensiones de la igualdad sustantiva (redistribución, reconocimiento, participación y transformación). Apreciamos, además, cómo los derechos particularizados de este grupo social y los deberes positivos de los Estados que regula la CDPD-ONU encontraron un esquema coherente bajo el cual es posible formular un análisis integral en procura de reparar la desventaja. Y es que, siendo multidimensional la desventaja, la respuesta jurídica también debe articularse de esta manera.

Por su parte, el segundo esquema que estudiamos fue el propuesto recientemente por el Tribunal Constitucional peruano bajo la noción de igualdad real de oportunidades. Al examinar tal concepto, ubicamos su origen en la teoría de la justicia de la filósofa Nancy Fraser y su noción de paridad participativa, el cual fue adaptado como una teoría de la igualdad por parte de la academia argentina. Vimos que el concepto que formuló el Tribunal se limitó a desarrollar solo dos escalas, la redistributiva y la de reconocimiento, omitiendo la escala de participación política, también trabajada por Fraser.

Presentado ambos esquemas, constatamos que el modelo de igualdad de la CDPD-ONU resulta ser más avanzado que el formulado por el Tribunal peruano, al subsumir los componentes de redistribución y reconocimiento del segundo en un enfoque multidimensional de cuatro puntos interrelacionados. Del mismo modo, no carga con los cuestionamientos teóricos de la noción de oportunidad, ni busca dimensionar en 
una sola perspectiva a sus componentes. Más allá de estas diferencias, concluimos que, siendo compatibles sus matrices teóricas, el modelo de igualdad inclusiva tras la CDPD-ONU puede complementar y guiar los futuros desarrollos de la concepción asimétrica de igualdad que establece el Tribunal Constitucional en materia de protección de los grupos desaventajados.

Si consideramos todo lo desarrollado hasta este punto, notaremos que hemos formulado tanto una forma de entender las desventajas en el caso de las personas con discapacidad mental, como también un esquema analítico adecuado para atender la naturaleza multidimensional de tales desventajas. Bajo estos dos parámetros, realizamos un enjuiciamiento teórico de la principal jurisprudencia desarrollada por el Tribunal Constitucional en materia de personas con discapacidad mental, con el objeto de mostrar sus desajustes.

Así, debemos señalar que el Tribunal mantuvo inicialmente una concepción patológica de la discapacidad mental, que lo llevó a dimensionar la desventaja de este grupo como una cuestión de salud y, por ende, individual. Es bajo este influjo que se desarrollan una serie de atributos sobre este grupo, que no corresponden al heterogéneo espectro de situaciones tras el concepto de discapacidad mental. Más aun, esta conceptualización derivó en un tratamiento desproporcional en atención a la inclusión de este grupo a la sociedad, al considerar la posibilidad de internamientos médicos indefinidos. Esta forma de analizar los casos que involucran personas con discapacidad mental fue modificada en una última sentencia del Tribunal, al virar hacia una definición construccionista de discapacidad. En este otro extremo, fundamentado en la CDPD-ONU, este alto Tribunal particulariza el derecho fundamental al libre tránsito al caso de una persona con discapacidad, pero no termina de asumir los propios postulados del modelo social que afirma adoptar. Sin un razonamiento estructural, deviene esta sentencia en una reparación individual. Esta particularización, por lo demás, no fue articulada con el principio-derecho de igualdad, razonamiento que era factible considerando lo transversal que es este concepto en la CDPD-ONU.

Como consecuencia de este análisis, debemos indicar que el Tribunal 
tiene aún el reto de desarrollar el concepto de igualdad real de oportunidades en el caso de las personas con discapacidad mental. Para ello, el enfoque asimétrico de igualdad que plantea el Tribunal debe ser ampliado, de tal modo que reconozca las dimensiones de ajustes y de participación del modelo de igualdad inclusiva de la CDPD-ONU. Esto permitirá brindar un marco adecuado para tratar los casos que involucren a las personas con discapacidad mental y que atienda todas las dimensiones que implican esta experiencia de desventaja. Esto debe ser reflejado en las reparaciones, que no deben limitarse a acciones positivas, sino también transformadoras, con objeto de enfrentar constitucionalmente el ciclo de desventaja de este grupo social. Asimismo, el Tribunal debería revisar la rigidez de sus conclusiones construccionista sobre la discapacidad, toda vez que la CDPD-ONU no le obliga a adoptar tal marco teórico y, sobre todo, puede derivar en la desprotección del elemento individual de la desventaja en los casos de personas con discapacidad mental.

Finalmente, otro reto implícito de todo enfoque igualitario basado en grupos desaventajados es evitar caer en esencialismos. El Tribunal por mucho tiempo afirmó una serie de características que no diferenciaba la heterogénea realidad tras la etiqueta de discapacidad mental, lo cual, sin duda, afecta la dimensión de reconocimiento de la igualdad. Este marco cultural inadecuado, por consiguiente, no tuvo en cuenta la realidad de las personas neurodiversas. Por eso es necesario que el Tribunal realice mayores esfuerzos de distinción, siendo la diversidad cognitiva que implica la experiencia humana una base para este propósito, a fin de no reforzar una serie de prejuicios construidos en torno a la idea de normalidad. Desde luego, las personas con discapacidad mental deben ser consideradas y respetadas también como expresiones humanas dignas, pero sin soslayar el hecho que su condición está compuesta, además de las barreras sociales y culturales, de una deficiencia individual a ser tratada.

\section{Bibliografía}

Аввотт, Andrew (1988): The system of professions. An essay on the división of expert labor (Chicago, The University of Chicago Press). 
Albertyn, Catherine (2007): "Substantive Equality and Transformation in South Africa”, en South African Journal on Human Rights, (Vol. 23, N 2), pp. 253-276.

Alemany, Macario (2018): "Igualdad y diferencia en relación con las personas con discapacidad. (Una crítica a la Observación N. ${ }^{\circ} 1$ (2014) del Comité (UN) de los derechos de las personas con discapacidad)", en Anales de la Cátedra Francisco Suárez ( ${ }^{\circ} 52$ ), pp. 201-222.

Areheart, Bradley (2011): "Disability trouble", en Yale Law \& Policy Review (Vol. 29, N²), pp. 347-388.

ARnARDÓtTIR, Oddný Mjöll (2009): "A Future of Multidimensional Disadvantage Equality?”, en ARnARdótTIR, Oddný Mjöll y QuinN, Gerard (eds.), The UN Convention on the Rights of Persons with Disabilities: European and Scandinavian perspectives (Leiden, Martinus Nijhoff Publishers), pp. 41-66.

Arstein-Kerslake, Anna (2017): Restoring voice to people with cognitive disabilities. Realizing the right to equal recognition before the law (Cambridge, Cambridge University Press).

Atienza, Manuel (2016): "Dignidad humana y derechos de las personas con discapacidad", en lus et Veritas ( $\mathrm{N}^{\circ} 53$ ), pp. 262-266.

BARESFORD, Peter (2002): "Thinking about "mental health": Towards a social model", en Journal of Mental Health (Vol. 11, $N^{\circ} 6$ ), pp. 581-584.

BICKENBACH, Jerome (2009): "Disability, culture and the UN convention", en Disability and Rehabilitation (Vol. 31, N¹4), pp. 1111-1124.

Boвbıo, Norberto (1991): El tiempo de los derechos (Madrid, Editorial Sistema).

Bosco, Alessandro, Schneider, Justine, Coleston-Shields, Donna Maria, Jawahar, Kaanthan, Higgs, Paul y Orrell, Martin (2018): "Agency in dementia care: systematic review and meta-ethnography", en International Psychogeriatrics (Vol. 31, № 5), pp. 1-16.

BOYLE, Geraldine (2014): "Recognising the agency of people with dementia”, en Disability \& Society (Vol, 29, № 7), pp. 1130-1144.

BRODERICK, Andrea (2015): The long and winding road to equality and inclusion for persons with disabilities. The United Nations Convention on the Rights of Persons with Disabilities (Maastricht, Maastricht 
University).

Brown, Phil (1995): "Naming and Framing: The Social Construction of Diagnosis and Illness" en Journal of Health and Social Behavior (Extra Issue: Forty Years of Medical Sociology: The State of the Art and Directions for the Future), pp. 34-52.

Bunge, Mario (2009): Los médicos ignoran la filosofía a su riesgo y al nuestro. ¿Qué es filosofar científicamente? Y otros ensayos (Lima, Fondo Editorial de la Universidad Inca Garcilaso de la Vega), pp. 145-164.

CARMACK, Heather (2014): "Social and Tertiary Health Identities as Argument in the DSM-V Asperger's/Autism Debate", en Western Journal of Communication (Vol. 78, N4), pp. 462-479.

Clark, Lee Anna, Cuthbert, Bruce, LeWis-Fernández, Roberto, Narrow, William y REED, Geoffrey (2017): "Three Approaches to Understanding and Classifying Mental Disorder: ICD-11, DSM-5, and the National Institute of Mental Health's Research Domain Criteria (RDoC)", en Psychological Science in the Public Interest (Vol. 18, N²), pp. 72-145.

Clarke, Adele, Shim, Janet, Mamo, Laura, Fosket, Jennifer Ruth y FISHMAN, Jennifer (2003): "Biomedicalization: Technoscientific Transformations of Health, Illness, and U.S. Biomedicine", en American Sociological Review (Vol. 68, N²), pp. 161-194.

ClÉRICO, Laura y AldAO, Martín (2011): "Nuevas miradas de la igualdad en la jurisprudencia de la Corte Interamericana de Derechos Humanos: la igualdad como redistribución y como reconocimiento", en Lecciones y Ensayos ( $\left.\mathrm{N}^{\circ} 89\right)$, pp. 141-179.

Comité sobre los Derechos de las Personas con Discapacidad (2018): Observación general número 6 sobre la igualdad y la no discriminación (Ginebra, Naciones Unidas).

ConRAD, Peter (2007): The medicalization of society. On the transformation of human conditions into treatable disorders (Baltimore, The Johns Hopkins University Press).

Corsı, Jessica Lynn (2018): "Article 5: Equality and Non-Discrimination”, en Bantekas, Ilias, Stein, Michael Ashley y AnAstasiou, Dimitris (eds.), The UN Convention on the Rights of Persons with Disabilities. A Commentary (Nueva York, Oxford University Press), pp. 140-170. 
CrIAdO, Marcos (2011): "La igualdad en el constitucionalismo de la diferencia”, en Revista Derecho del Estado (N²6), pp. 7-49

Degener, Theresia (2016): "Disability in a Human Rights Context", en Laws (Vol. 5, N³), pp. 1-24.

DíAz dE VALDÉS, José Manuel (2015): "La igualdad constitucional: múltiple y compleja", en Revista Chilena de Derecho (Vol. 42, $\mathrm{N}^{\circ} 1$ ), pp. 153-187.

Double, Duncan (2002): "The limits of psychiatry", en BMJ (Vol. 324, $\mathrm{N}^{\circ}$ 7342), pp. 900-904.

DYck, Erika y RusseLL, Ginny (2020): "Challenging psychiatric classification: healthy autistic diversity and the neurodiversity movement", en TAYLOR, Steven y BRUmBY, Alice (eds.), Healthy minds in the Twentieth Century. In and beyond the asylum (Londres, Palgrave Macmillan), pp. 167-187.

FEnTON, Andrew y KRAHN, Tim (2007): "Autism, Neurodiversity and Equality Beyond the "Normal"', en Journal of Ethics in Mental Health (Vol, 2, $\mathrm{N}^{\circ} 2$ ), pp. 1-6.

FINCHMAN, Robin y Forbes, Tom (2019): "Counter-rhetoric and sources of enduring conflict in contested organizational fields: A case study of mental health professionals", en Journal of Professions and Organization (Vol. 6, $\mathrm{N}^{\circ} 3$ ), pp. 342-356.

FioravantI, Maurizio (2016): Los derechos fundamentales. Apuntes de historia de las constituciones, $7^{\mathrm{a}}$ ed. (Madrid, Trotta).

FRASER, Nancy (1996): "Redistribución y reconocimiento. Hacia una visión integrada de justicia del género", en Revista Internacional de Filosofía Política (N8), pp. 18-40.

FRASER, Nancy (2010): "Injustice at Intersecting Scales: On "Social Exclusion" and the "Global Poor"', en European Journal of Social Theory (Vol. 13, N³), pp. 363-371.

Fredman, Sandra (2011). Discrimination law, $2^{a}$ ed. (Nueva York, Oxford University Press).

Fredman, Sandra, Campbell, Meghan, Atrey, Shreya, BrickHill, Jason, Ramalekana, Nomfundo y Samtani, Sanya (2017): Achieving Transformative Equality for Persons with Disabilities: Submission to the CRPD 
Committee for General Comment No. 6 on Article 5 of the UN Convention on the Rights of Persons with Disabilities (Oxford, Oxford Human Rights Hub).

Gargarella, Roberto (2014): La sala de máquinas de la Constitución. Dos siglos de constitucionalismo en América Latina (1810-2010) (Buenos Aires, Katz).

Gómez, Erick y CAstillo, Dídimo (2016): "Sociología de la discapacidad", en Tla-Melaua, Revista de Ciencias Sociales (Vol. 10, № 40), pp. 176-194.

Goodley, Dan, LaWthom, Rebecca, Liddiard, Kirsty y Runswick-Cole, Katherine (2019): "Provocations for Critical Disability Studies", en Disability \& Society (Vol. 34, N 6), pp. 972-997.

Grosman, Lucas (2008). Escasez e igualdad. Los derechos sociales en la Constitución (Libraria, Buenos Aires).

HACKING, Ian (1999): The social construction of what? (Cambridge (M.), Harvard University Press).

Hens, Manuel, Foronda, Jesús, Montes, Juan, Nieto, Inmaculada, Cobo, Manuela, QueSADA, Juan y CAMACHO, Bernardo (2009): "Enfermedad de Whipple: una infrecuente causa bacteriana de demencia", en Revista de la Asociación Española de Neuropsiquiatría (Vol. 29, № 104), pp. 535-538.

Huber, Machteld, Knottnerus, André, Green, Lawrence, van der Horst, Henriëtte, Jadad, Alejandro, Kromhout, Daan, Leonard, Brian, Lorig, Kate, Loureiro, Maria Isabel, van der Meer, Jose, Schnabel, Paul, SmlTH, Richard, van WEeL, Chris y SMID, Henk (2011): "How should we define health?", en BMJ (Vol. 343, $\mathrm{N}^{\circ}$ d4163), pp. 1-3.

Huerta, Luis (2005): "El derecho a la igualdad", en Pensamiento Constitucional ( $\left.\mathrm{N}^{\circ} 11\right)$, pp. 307-334.

Hughes, Bill (2012): "Fear, pity and disgust. Emotions and the non-disabled imaginary", en Watson, Nick, Roulstone, Alan y Thomas, Carol (eds.), Routledge handbook of disability studies (Abingdon, Routledge), pp. 67-77.

Human Rights Watch (2012): "Yo quiero ser una ciudadana como cualquier otra”. Obstáculos para la participación política de personas con 
discapacidad en Perú (Estados Unidos, Human Rights Watch).

Hyman, Steven (2010): "The Diagnosis of Mental Disorders: The Problem of Reification", en Annual Review of Clinical Psychology ( $\left.{ }^{\circ} 6\right)$, pp. 155-179.

Kakoullis, Emily e Ikehara, Yoshikazu (2018): “Article 1: Purpose”, en Bantekas, Ilias, SteIn, Michael Ashley y Anastasiou, Dimitris (eds.), The UN Convention on the Rights of Persons with Disabilities. A Commentary (Nueva York, Oxford University Press), pp. 35-62.

Kapp, Steven, Gillespie-Lynch, Kristen, Sherman, Lauren y Hutman, Ted (2012): "Deficit, difference, or both? Autism and neurodiversity", en Developmental Psychology (Vol. 49, № 1), pp. 59-71.

Keen, Daphne, ReID, Fiona y Arnone, Danilo (2010): “Autism, ethnicity and maternal immigration", en The British Journal of Psychiatry ( $\left.\mathrm{N}^{\circ} 196\right)$, pp. 274-281.

Leonardi, Matilde, Bickenbach, Jerome, Bedirhan Ustun, Tevfik, KostanJSEK, Nenad y CHATTERJI, Somnath (2006): "The definition of disability: What is in a name?", en The Lancet (Vol. 368, N 9543), pp. 1219-1221. LoLLINI, Andrea (2018): "Brain equality: Legal implications of neurodiversity in a comparative perspective", en New York University Journal of International Law and Politics ( ${ }^{\circ} 51$ ), pp. 69-133.

LoRD, Janet (2018): "Preamble", en Bantekas, Ilias, Stein, Michael Ashley y Anastasiou, Dimitris (eds.), The UN Convention on the Rights of Persons with Disabilities. A Commentary (Nueva York, Oxford University Press), pp. 1-34.

MÉGRET, Frédéric (2008): "The Disabilities Convention: Human Rights of Persons with Disabilities or Disability Rights?”, en Human Rights Quarterly (Vol. 30, N²), pp. 494-516.

Nogueira, Humberto (2006): "El derecho a la igualdad ante la ley, no discriminación y acciones positivas", en Revista de Derecho de la Universidad Católica del Norte (Vol. 13, N²), pp. 61-100.

Nussbaum, Martha (2007): Las fronteras de la justicia. Consideraciones sobre la exclusión (Barcelona, Paidós).

Oliver, Mike y Barnes, Colin (2012): The New Politics of Disablement (Basingstoke, Palgrave Macmillan). 
O’Reilly, Michelle, Lester, Jessica Nina y Kiyımba, Nikki (2020): “Autism in the Twentieth Century: An Evolution of a Controversial Condition”, en TAYLOR, Steven y Brumby, Alice (eds.), Healthy minds in the Twentieth Century. In and beyond the asylum (Londres, Palgrave Macmillan), pp. 137-164.

Organización Mundial de la Salud (2001): Clasificación internacional del funcionamiento, de la discapacidad y de la salud: CIF (Ginebra, Organización Mundial de la Salud).

Ortega, Francisco (2009): "The cerebral subject and the challenge of neurodiversity", en BioSocieties (Vol. 4, N 4), pp. 425-445.

Palacios, Agustina (2008): El modelo social de discapacidad: orígenes, caracterización y plasmación en la Convención Internacional sobre los Derechos de las Personas con Discapacidad (Madrid, CERMI).

Palmer, Michael y HARLEY, David (2012): "Models and measurement in disability: an international review", en Health Policy and Planning $\left(\mathrm{N}^{\circ}\right.$ 27), pp. 357-364.

RADDEN, Jennifer (2019): "Mental Disorder (Illness)", en ZALTA, Edward (ed.). The Stanford Encyclopedia of Philosophy, [fecha de consulta: 17 de diciembre de 2019]. [Disponible en: https://plato.stanford.edu/ entries/mental-disorder/].

Ramírez, Beatriz (2013): El "estado de cosas inconstitucional" y sus posibilidades como herramienta para el litigio estratégico de derecho público. Una mirada a la jurisprudencia colombiana y peruana (Lima, Pontificia Universidad Católica del Perú).

RodRíguez, Roger (2015): Una teoría sobre la derrotabilidad jurídica en el Estado Constitucional (Getafe, Instituto de Derechos Humanos "Bartolomé de las Casas").

Rogers, Anne y PILGRIM, David (2005): A sociology of mental health and illness, $3^{\mathrm{a}}$ ed. (Nueva York, Open University Press).

Ronconi, Liliana (2019), "Repensando el principio de igualdad: alcances de la igualdad real”, en Isonomía ( $\left.{ }^{\circ} 49\right)$, pp. 103-140.

SABA, Roberto (2012): Pobreza, derechos y desigualdad estructural (México, Suprema Corte de Justicia de la Nación, Tribunal Electoral del Poder Judicial de la Federación, Instituto Electoral del Distrito Federal). 
SCHACHT, Thomas (1992): "DSM-III and the politics of truth", en MILLER, Ronald (ed), The restoration of dialogue: Readings in the philosophy of clinical psychology (Washington, American Psychological Association), pp. 216-228.

SCHALOCK, Robert y LUCKASSON, Ruth (2013): "What's at stake in the lives of people with intellectual disability? Part I: The power of naming, defining, diagnosing, classifying, and planning supports", en Intellectual and Developmental Disabilities (Vol. 51, N²), pp. 86-93.

SeRIES, Lucy (2015): "Relationships, autonomy and legal capacity: Mental capacity and support paradigms", en International Journal of Law and Psychiatry ( $\left.{ }^{\circ} 40\right)$, pp. 80-91.

SHAKESPEARE, Tom (2014): Disability rights and wrongs revisited, 2a ed. (Abingdon, Routledge).

SHILDRICK, Margrit (2012): "Critical disability studies: rethinking the conventions for the age of postmodernity", en Watson, Nick, Roulstone, Alan y Thomas, Carol (eds.), Routledge handbook of disability studies (Abingdon, Routledge), pp. 30-41.

SLORACH, Roddy (2014): "Out of the shadows: disability movements", en Critical and Radical Social Work (Vol. 2, N²), pp. 159-174.

Thomas, Carol y Milligan, Christine (2017): "Dementia, disability rights and disablism: understanding the social position of people living with dementia", en Disability \& Society (Vol. 33, N¹), pp. 115-131.

TraustadótTIR, Rannveig (2009): "Disability Studies, the Social Model and Legal Developments", en en ARnardótTIR, Oddný Mjöll y QuinN, Gerard (eds.), The UN Convention on the Rights of Persons with Disabilities: European and Scandinavian perspectives (Leiden, Martinus Nijhoff Publishers), pp. 3-16.

Treuthart, Mary Pat (2018): "Article 39: Report of the Committee", en Bantekas, Ilias, Stein, Michael Ashley y Anastasiou, Dimitris (eds.), The UN Convention on the Rights of Persons with Disabilities. A Commentary (Nueva York, Oxford University Press), pp. 1119-1134.

Tully, James (1995): Strange multiplicity: constitutionalism in an age of diversity (Cambridge, Cambridge University Press).

Vargas, Martín, Lahera, Guillermo, López de Silanes, Carlos y TiRapu, Ja- 
vier (2011): "Proyecto de Sección de Neurociencia Clínica de la AEN", en Revista de la Asociación Española de Neuropsiquiatría ( $\left.\mathrm{N}^{\circ} 31\right)$, pp. 589-599.

VARGAS, Martín (2012): "Ni neurología desalmada, ni psiquiatría descerebrada: neurociencia clínica”, en Kranion ( $\mathrm{N}^{\circ}$ 9), pp. 11-15.

Velasco, Juan Carlos (2004): "Republicanismo, constitucionalismo y diversidad cultural. Más allá de la tolerancia liberal", en Revista de Estudios Políticos (Nueva Época) (N¹25), pp. 181-209.

WalmsLeY, Jan (2020): "Healthy Minds and Intellectual Disability", en TAYLOR, Steven y BRUmBY, Alice (eds.), Healthy minds in the Twentieth Century. In and beyond the asylum (Londres, Palgrave Macmillan), pp. 95-111.

Weller, Penelope (2018): “Article 25: Health”, en Bantekas, Ilias, Stein, Michael Ashley y Anastasiou, Dimitris (eds.), The UN Convention on the Rights of Persons with Disabilities. A Commentary (Nueva York, Oxford University Press), pp. 705-733.

Vehmas, Simo y Watson, Nick (2014): "Moral wrongs, disadvantages, and disability: a critique of critical disability studies", en Disability \& Society (Vol. 29, N4), pp. 638-650.

VICTORIA, Jorge (2013): "El modelo social de la discapacidad: una cuestión de derechos humanos", en Revista de Derecho UNED ( $\left.N^{\circ} 12\right)$, pp. 817-833.

Young, Iris Marion (1990): Justice and the politics of difference (Princeton, Princeton University Press).

Young, Iris Marion (2002): "Status inequality and social groups", en Issues in Legal Scholarship (Vol, 2, N¹), pp. 1-10.

ZAGREBELSKY, Gustavo (2011): El derecho dúctil, 10ª ed. (Madrid, Trotta).

\section{Normas jurídicas citadas}

Constitución Nacional Argentina (1853, revisada en 1994).

Constitución Política del Perú (1993).

Convención sobre los Derechos de las Personas con Discapacidad (2008). 
Decreto Supremo N007-2020-SA, que aprueba el Reglamento de la Ley $N^{\circ} 30947$, Ley de Salud Mental (El Peruano, 5 de marzo de 2020).

Decreto Supremo N 073-2007-RE, que ratifica la "Convención sobre los Derechos de las Personas con Discapacidad y su Protocolo Facultativo" (El Peruano, 31 de diciembre de 2007).

Ley N²6842, Ley General de la Salud (El Peruano, 20 de julio de 1997).

\section{Jurisprudencia citada}

Corte Constitucional de Colombia. Suministro y pago de terapias especializadas no comprendidas en el Plan de Beneficios, dirigidas a niños con presuntas alteraciones físicas, sensoriales o cognitivas (2019). Sentencia T 563 de 20 de noviembre de 2019. M.P. Luis Guillermo Guerrero Pérez.

Corte Interamericana de Derechos Humanos. Caso Gonzales Lluy y otros vs. Ecuador (2015). Excepciones preliminares, fondo, reparaciones y costas], sentencia. Sentencia de 1 de septiembre de 2015 . Serie $C^{\circ} N^{\circ}$ 298.

Corte Interamericana de Derechos Humanos. Caso Furlán y familiares vs. Argentina (2012). Excepciones preliminares, fondo, reparaciones y costas. Sentencia de 31 de agosto de 2012. Serie C N 246.

Tribunal Constitucional del Perú. Melchora Castañeda Tuesta de Flores, a favor de M.H.F.C. c. resolución de la Cuarta Sala Especializada en lo Penal para Procesos con Reos en Cárcel de la Corte Superior de Justicia de Lima [proceso de habeas corpus] (2019). Sentencia de 27 de junio de 2019. Expediente 04007-2015-PHC.

Tribunal Constitucional del Perú. José Antonio Guillén Tejada c. resolución de la Primera Sala Penal de Apelaciones de la Corte Superior de Justicia de Arequipa [proceso de habeas corpus]. Sentencia de 30 de abril de 2019. Expediente 00194-2014-PHC.

Tribunal Constitucional del Perú. Duberlis Nina Cáceres Ramos c. resolución de la Sala Mixta de la Corte Superior de Justicia de Madre de Dios [proceso de amparo] (2019). Sentencia de 5 de marzo de 2019. Expediente 01272-2017-PA. 
Tribunal Constitucional del Perú. Marleni Cieza Fernández y Elita Cieza Fernández c. resolución de la Sala Mixta de Utcubamba de la Corte Superior de Justicia de Amazonas [proceso de amparo] (2017). Sentencia de 14 de marzo de 2017. Expediente 00853-2015-PA.

Tribunal Constitucional del Perú. 25\% del número legal de congresistas c. Congreso de la República [proceso de inconstitucionalidad] (2012). Sentencia de 10 de abril de 2012 (El Peruano, 25 de abril de 2012). Expediente 0033-2010-PI.

Tribunal Constitucional del Perú. Pedro Gonzalo Marroquín Soto c. sentencia de la Primera Sala Penal de Reos en Cárcel de la Corte Superior de Justicia de Lima Norte [proceso de habeas corpus] (2010). Sentencia de 26 de agosto de 2010. Expediente 03426-2008-PHC.

Tribunal Constitucional del Perú. Luz Margarita Bustamante Candiotti c. sentencia expedida por la Segunda Sala Penal de la Corte Superior de Justicia de Lima [proceso de habeas corpus] (2009). Sentencia de 24 de septiembre de 2009. Expediente 2313-2009-HC.

Tribunal Constitucional del Perú. Miguel Ángel Morales Denegri a favor de los internados en la sala de hospitalización de adicciones del Instituto Nacional de Salud Mental Honorio Delgado-Hideyo Noguchi c. sentencia de la Segunda Sala Penal de Procesos con Reos Libres de la Corte Superior de Justicia de Lima [proceso de habeas corpus] (2008). Sentencia de 7 de noviembre de 2008. Expediente 05842-2006-PHC. Tribunal Constitucional del Perú. Matilde Villafuerte viuda de Medina, en su calidad de curadora de Ramón Medina Villafuerte c. sentencia de la Segunda Sala Civil de la Corte Superior de Justicia de Lima [proceso de amparo] (2008). Sentencia de 11 de julio de 2008. Expediente 02480-2008-PA.

Tribunal Constitucional del Perú. R.J.S.A. viuda de R., a nombre propio y en su calidad de curadora representante de su hija G. R. S. c. sentencia de la Quinta Sala Civil de la Corte Superior de Justicia de Lima [proceso de amparo] (2007). Sentencia de 9 de septiembre de 2007. Expediente 3081-2007-PA.

Tribunal Constitucional del Perú. José Miguel Morales Dasso, en representación de cinco mil ciudadanos c. Congreso de la República [proce- 
so de inconstitucionalidad] (2005). Sentencia de 1 de abril de 2005 (El Peruano, 7 de abril de 2005). Expediente 0048-2004-PI.

Tribunal Constitucional del Perú. Víctor Manuel Otoya Petit c. sentencia de la Tercera Sala Civil de la Corte Superior de Justicia de Lima [proceso de amparo] (2004). Sentencia de 28 de junio de 2004. Expediente 0606-2004-AA. 